\title{
Discovery of a Potent Anticancer Agent PVHD303 with in Vivo Activity
}

Yumiko Suzuki, ${ }^{* \dagger}{ }^{\dagger}$ Ayana Otake, ${ }^{\ddagger}$ Satoshi Ueno,\# Kensuke Hayashi, ${ }^{\dagger}$ Hirosuke Ishii, ${ }^{\natural}$ Nao Miyoshi, ${ }^{\natural}$

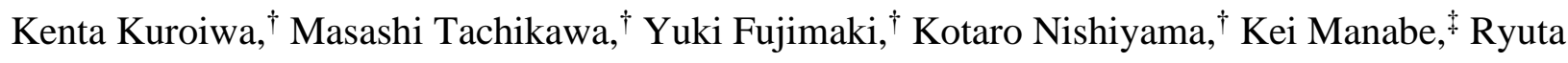

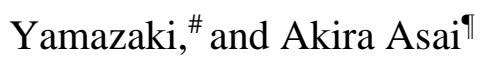

$\dagger$ Department of Materials and Life Sciences, Faculty of Science and Technology, Sophia University, 7-1 Kioi-cho, Chiyoda-ku, Tokyo 102-8554, Japan.

$¥$ School of Pharmaceutical Sciences, University of Shizuoka, 52-1 Yada, Suruga-ku, Shizuoka 422-8526, Japan. \#Pharmaceutical Research Department, Yakult Central Institute, 5-11 Izumi, Kunitachi-shi, Tokyo 186-8650, Japan.

IIGraduate School of Pharmaceutical Sciences, University of Shizuoka, 52-1 Yada, Suruga-ku, Shizuoka 422-8526, Japan

\section{Contents}

1. Chemistry

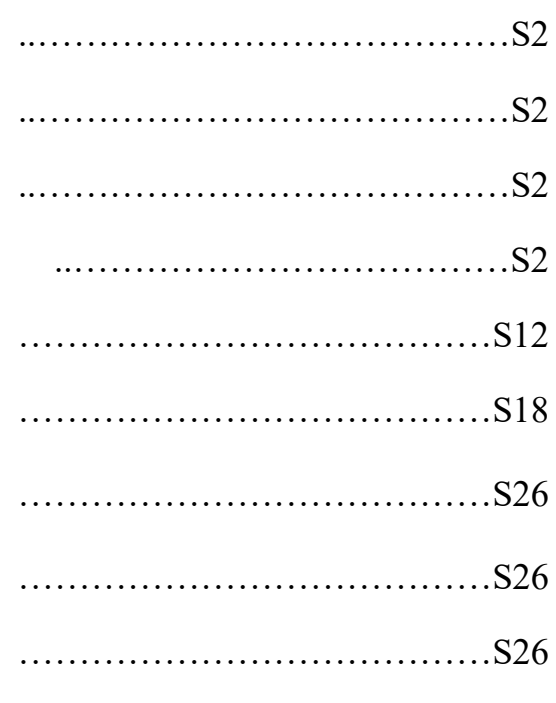

3. References 


\section{Chemistry}

\subsection{Scheme S-1 Synthesis of 3a}

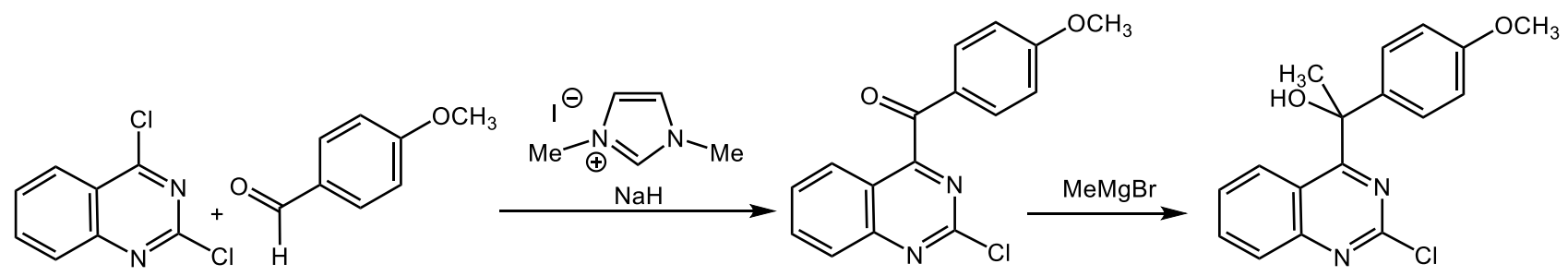

Scheme S-1. Synthesis of $3 a .^{1}$

\subsection{General Information}

Reagents and solvents were purchased from commercial sources and used without further purification. All reactions were performed under argon and stirring unless otherwise noted. Column chromatography was performed using spherical silica gel (63-219 $\mu \mathrm{m})$ (Kanto Chemicals). For thin-layer chromatography (TLC) analysis, Merck TLC plates (silica gel 60G F254 $0.25 \mathrm{~mm}$ ) were used. The TLC plates were visualized by fluorescence under a UV lamp (254 or $365 \mathrm{~nm}$ ). Melting points were measured using an ATM-02, AS ONE melting point apparatus and were uncorrected. Purity of all tested compounds was estimated as $>95 \%$ by HPLC (HITACHI LaChrom) analysis on the Inertsil ODS-3 (GL Sciences Inc.) column $(4.6 \times 250 \mathrm{~mm}, 5 \mu \mathrm{m})$, and by proton nuclear magnetic resonance $\left({ }^{1} \mathrm{H}\right.$ NMR) spectra. Retention times are recorded in minites. ${ }^{1} \mathrm{H}$ NMR spectra were recorded on a JEOL JNM-ECX (300 and $500 \mathrm{MHz}$ ) spectrometer. Chemical shifts were recorded in parts per million (ppm, $\delta$ ), relative to tetramethylsilane $(\delta 0.00) .{ }^{1} \mathrm{H}$ NMR splitting patterns are designated as singlet (s), doublet (d), triplet $(\mathrm{t})$, dd (doublet of doublets), $\mathrm{dt}$ (doublet of triplets), $\mathrm{m}$ (multiplets), etc. Carbon nuclear magnetic resonance $\left({ }^{13} \mathrm{C}\right.$ NMR) spectra were recorded on a JEOL JNM-ECX $(75,100$, and $125 \mathrm{MHz})$ spectrometer. Mass spectra were recorded using a TOF (ESI) analyzer, or a magnetic sector $(\mathrm{FAB})$ analyzer.

\subsection{Synthesis of compound 4-7 (Compounds in Table 1)}

\subsubsection{Synthesis of 1-(5-fluoroquinazolin-4-yl)-1-(4-methoxyphenyl)ethan-1-ol (4a)}<smiles>COc1ccc(C(=O)c2cnc3ccc(C)c(C(=O)c4ncnc5ccc(F)cc45)c3c2)cc1</smiles>

\section{General procedure A}

Under an atmosphere of argon, a solution of 4-dichloro-5-fluoroquinazoline SM4a² (205 mg, $1.12 \mathrm{mmol}$ ) and 1,3dimethylimidazolium iodide $\mathbf{S 2}(28.0 \mathrm{mg}, 0.12 \mathrm{mmol})$ in THF $(5 \mathrm{~mL})$ and DMF $(3 \mathrm{~mL})$ was stirred for $5 \mathrm{~min}$ at room temperature. Then 4-anisaldehyde $\mathbf{S} 1(0.14 \mathrm{~mL}, 1.13 \mathrm{mmol})$ and sodium hydride $(63.0 \mathrm{mg}, 1.31 \mathrm{mmol})$ were added to the solution at $0{ }^{\circ} \mathrm{C}$. The mixture was refluxed for $2 \mathrm{~h}$, and then poured into ice water. The product was extracted with ethyl acetate. The organic layer was washed with brine, dried over $\mathrm{Na}_{2} \mathrm{SO}_{4}$, filtered, and evaporated. The residue was purified by silica gel column chromatography ( $n$-hexane: ethyl acetate $=4: 1)$ to afford compound pre-4a (159 mg, $0.56 \mathrm{mmol}, 50 \%)$.

Mp: $137-138^{\circ} \mathrm{C}$. 
${ }^{1} \mathrm{H}-\mathrm{NMR}\left(500 \mathrm{MHz}, \mathrm{CDCl}_{3}\right) \delta: 3.89(3 \mathrm{H}, \mathrm{s}), 6.96(2 \mathrm{H}, \mathrm{d}, J=8.6), 7.30-7.33(1 \mathrm{H}, \mathrm{m}), 7.82(2 \mathrm{H}, \mathrm{d}, J=8.6), 7.89-$ $8.01(2 \mathrm{H}, \mathrm{m}), 9.42(1 \mathrm{H}, \mathrm{s})$.

${ }^{13} \mathrm{C}-\mathrm{NMR}\left(126 \mathrm{MHz}, \mathrm{CDCl}_{3}\right) \delta: 55.6,112.9,113.2,114.2,125.1$ (d, $\left.J=4.4 \mathrm{~Hz}\right), 127.5$ (d, J=2.8 Hz), 132.6, 134.8 (d, $J=9.4 \mathrm{~Hz}), 151.6,154.8$ (d, $J=1.4 \mathrm{~Hz}), 157.0$ (d, $J=263 \mathrm{~Hz}), 163.4$ (d, $J=3.5 \mathrm{~Hz}), 164.6,191.1$.

HRMS (FAB) $m / z$ Calcd forC $\mathrm{C}_{16} \mathrm{H}_{12} \mathrm{FN}_{2} \mathrm{O}_{2}(\mathrm{M}+\mathrm{H})^{+}:$283.0883, Found:283.0889.

\section{General procedure B}

Under an atmosphere of argon, methylmagnesium bromide in THF $(1.6 \mathrm{~mL}, 1.456 \mathrm{mmol})$ was added to a solution of compound pre-4a (148 mg, $0.525 \mathrm{mmol})$ in THF $(3 \mathrm{~mL})$. The solution was stirred for $4.0 \mathrm{~h}$ at $0{ }^{\circ} \mathrm{C}$. The reaction mixture was poured into ice water, neutralized with hydrochloric acid. The product was extracted with ethyl acetate. The organic layer was washed with brine, dried over $\mathrm{Na}_{2} \mathrm{SO}_{4}$, filtered, and evaporated. The residue was purified by silica gel column chromatography ( $n$-hexane: dichloromethane: ethyl acetate $=10: 5: 1)$ to afford compound $4 \mathbf{a}(69.1$ $\mathrm{mg}, 0.232 \mathrm{mmol}, 44 \%)$.

Mp: $97-98^{\circ} \mathrm{C}$.

${ }^{1} \mathrm{H}-\mathrm{NMR}\left(500 \mathrm{MHz}, \mathrm{CDCl}_{3}\right) \delta: 2.05(3 \mathrm{H}, \mathrm{d}, J=1.6 \mathrm{~Hz}), 3.74(3 \mathrm{H}, \mathrm{s}), 6.56(1 \mathrm{H}, \mathrm{s}), 6.77(2 \mathrm{H}, \mathrm{d}, J=8.9 \mathrm{~Hz}), 7.16-$ $7.69(3 \mathrm{H}, \mathrm{m}), 7.79(1 \mathrm{H}, \mathrm{td}, J=8.2,5.4 \mathrm{~Hz}), 7.94(1 \mathrm{H}, \mathrm{dd}, J=8.4,1.2 \mathrm{~Hz}), 9.31(1 \mathrm{H}, \mathrm{s})$.

${ }^{13} \mathrm{C}-\mathrm{NMR}\left(126 \mathrm{MHz}, \mathrm{CDCl}_{3}\right) \delta: 27.0(\mathrm{~d}, J=9.3 \mathrm{~Hz}), 55.1,76.7,113.1(\mathrm{~d}, J=15.3 \mathrm{~Hz}), 113.4,114.1(\mathrm{~d}, J=24 \mathrm{~Hz})$, $125.8(\mathrm{~d}, J=4.4 \mathrm{~Hz}), 127.1$ (d, $J=3.0 \mathrm{~Hz}), 133.9$ (d, $J=10.2 \mathrm{~Hz}), 137.3$ (d, $J=4.3 \mathrm{~Hz}), 152.2,152.2(\mathrm{~d}, J=1.4$ $\mathrm{Hz}), 155.9(\mathrm{~d}, J=263 \mathrm{~Hz}), 158.5,171.4(\mathrm{~d}, J=6.8 \mathrm{~Hz})$.

HRMS (FAB) $\mathrm{m} / \mathrm{z}$ Calcd for $\mathrm{C}_{17} \mathrm{H}_{16} \mathrm{FN}_{2} \mathrm{O}_{2}(\mathrm{M}+\mathrm{H})^{+}: 299.1196$,Found: 299.1195.

RT: 8.72 (EtOH: $\left.\mathrm{H}_{2} \mathrm{O}=1: 1,1 \mathrm{~mL} / \mathrm{min}\right)$

\subsubsection{Synthesis of 1-(6-fluoroquinazolin-4-yl)-1-(4-methoxyphenyl)ethan-1-ol (5a)}

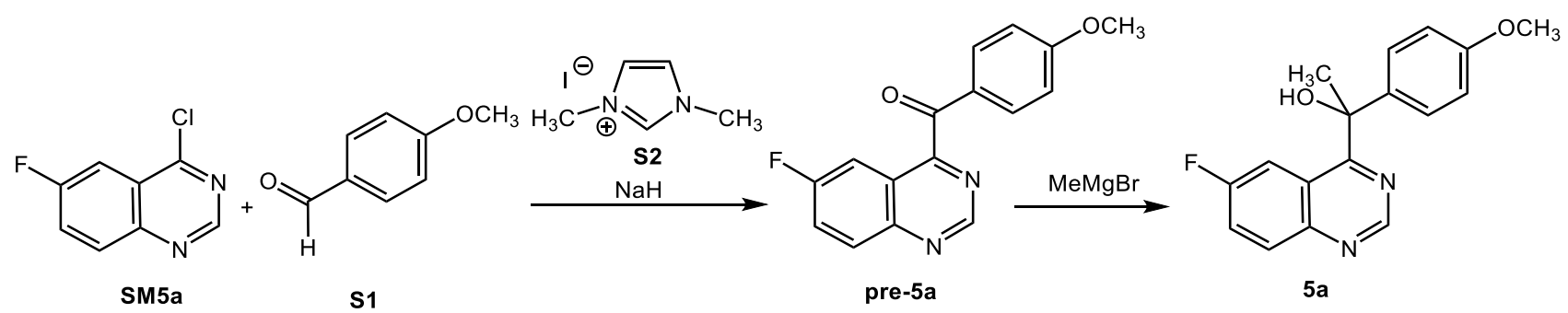

According to the general procedure A, pre-5a was synthesized: $\mathbf{S 1}(0.45 \mathrm{~mL}, 3.64 \mathrm{mmol})$ and sodium hydride (197 $\mathrm{mg}, 4.10 \mathrm{mmol}$ ) were added to a solution of 4-chloro-6-fluoroquinazoline SM5a ${ }^{3,4}$ (591 mg, $3.24 \mathrm{mmol}$ ) and $\mathbf{S 2}$ (81.4 mg, $0.363 \mathrm{mmol})$ in THF $(18 \mathrm{~mL})$ and DMF $(10 \mathrm{~mL})$ at $0{ }^{\circ} \mathrm{C}$. The mixture was refluxed for $1 \mathrm{~h}$ to afford pre5a (764 mg, $2.71 \mathrm{mmol}, 84 \%$ ) and the starting material SM5a (10.7 mg, $0.059 \mathrm{mmol}, 2 \%)$.

Mp: $136-137^{\circ} \mathrm{C}$.

${ }^{1} \mathrm{H}-\mathrm{NMR}\left(500 \mathrm{MHz}, \mathrm{CDCl}_{3}\right) \delta: 3.90(3 \mathrm{H}, \mathrm{s}), 6.98(2 \mathrm{H}, \mathrm{d}, J=8.8 \mathrm{~Hz}), 7.72-7.77(2 \mathrm{H}, \mathrm{m}), 7.96(2 \mathrm{H}, \mathrm{d}, J=8.8 \mathrm{~Hz})$, $8.18(1 \mathrm{H}, \mathrm{dd}, J=10.0,5.1 \mathrm{~Hz}), 9.41(1 \mathrm{H}, \mathrm{s})$.

${ }^{13} \mathrm{C}-\mathrm{NMR}\left(126 \mathrm{MHz}, \mathrm{CDCl}_{3}\right) \delta: 55.6,109.5(\mathrm{~d}, J=23.7 \mathrm{~Hz}), 114.1,122.7(\mathrm{~d}, J=10.1 \mathrm{~Hz}), 125.2(\mathrm{~d}, J=26.1 \mathrm{~Hz})$, 127.9, 131.7 (d, $J=8.8 \mathrm{~Hz}), 133.2,148.5,153.2$ (d, $J=2.8 \mathrm{~Hz}), 161.0$ (d, $J=254 \mathrm{~Hz}), 163.6$ (d, $J=6.5 \mathrm{~Hz}), 164.8$, 190.8 .

According to the general procedure B, 5a was synthesized from pre-5a: Methylmagnesium bromide in THF (4.4 mL, 
$4.05 \mathrm{mmol})$ was added to a solution of pre-5a $(464 \mathrm{mg}, 1.64 \mathrm{mmol})$ in THF $(15 \mathrm{~mL})$. The solution was stirred for 4 $\mathrm{h}$ at $0{ }^{\circ} \mathrm{C}$. The product was purified by column chromatography ( $n$-hexane: dichloromethane: ethyl acetate $=10: 5$ : 2) afforded 5a (240 mg, $0.803 \mathrm{mmol}, 49 \%)$.

Mp: $136-137^{\circ} \mathrm{C}$.

${ }^{1} \mathrm{H}-\mathrm{NMR}\left(500 \mathrm{MHz}, \mathrm{CDCl}_{3}\right) \delta: 2.09(3 \mathrm{H}, \mathrm{s}), 3.79(3 \mathrm{H}, \mathrm{s}), 6.11(1 \mathrm{H}, \mathrm{s}), 6.86(2 \mathrm{H}, \mathrm{d}, J=8.9 \mathrm{~Hz}), 7.30(2 \mathrm{H}, \mathrm{d}, J=8.9$ $\mathrm{Hz}), 7.39(1 \mathrm{H}, \mathrm{dd}, J=9.7,2.7 \mathrm{~Hz}), 7.57(1 \mathrm{H}, \mathrm{ddd}, J=10.0,7.2,2.9 \mathrm{~Hz}), 8.08(1 \mathrm{H}, \mathrm{dd}, J=9.2,5.4 \mathrm{~Hz}), 9.31(1 \mathrm{H}, \mathrm{s})$. ${ }^{13} \mathrm{C}-\mathrm{NMR}\left(126 \mathrm{MHz}, \mathrm{CDCl}_{3}\right) \delta: 28.8,55.2,75.4,110.4(\mathrm{~d}, J=14.4 \mathrm{~Hz}), 114.2(\mathrm{~d}, J=18.8 \mathrm{~Hz}), 122.1$ (d, $\left.J=5.9 \mathrm{~Hz}\right)$, $123.9(\mathrm{~d}, J=15.6 \mathrm{~Hz}), 127.4,131.9(\mathrm{~d}, J=5.5 \mathrm{~Hz}), 136.9,148.3,151.8,159.1,159.6(\mathrm{~d}, J=152 \mathrm{~Hz}), 172.2(\mathrm{~d}, J=$ $3.5 \mathrm{~Hz})$.

HRMS (FAB) $m / z$ Calcd for $\mathrm{C}_{17} \mathrm{H}_{16} \mathrm{FN}_{2} \mathrm{O}_{2}(\mathrm{M}+\mathrm{H})^{+}: 299.1196$,Found: 299.1203.

RT: 10.59 (EtOH: $\mathrm{H}_{2} \mathrm{O}=1: 1,1 \mathrm{~mL} / \mathrm{min}$ )

\subsubsection{Synthesis of 1-(6-chloroquinazolin-4-yl)-1-(4-methoxyphenyl)ethan-1-ol (5b)}

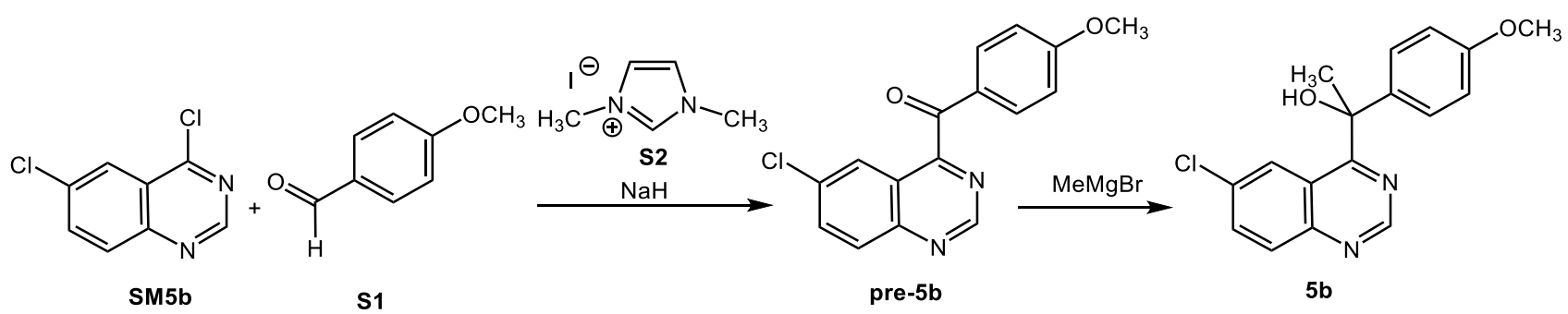

According to the general procedure A, pre-5b was synthesized: $\mathbf{S 1}(500 \mu \mathrm{L}, 3.9 \mathrm{mmol})$ and sodium hydride (120 $\mathrm{mg}$, $4.98 \mathrm{mmol})$ were added to a solution of 4,6-dichloroquinazoline $\mathbf{S M 5 \mathbf { b } ^ { 5 }}$ (694 $\left.\mathrm{mg}, 3.49 \mathrm{mmol}\right)$ and $\mathbf{S 2}$ ((104 $\mathrm{mg}, 0.46$ $\mathrm{mmol})$ in THF $(25 \mathrm{~mL})$ and DMF $(2 \mathrm{~mL})$ at $0{ }^{\circ} \mathrm{C}$. The mixture was refluxed for $1.5 \mathrm{~h}$ to afford compound pre-5b (589 mg, 61\%).

Mp $124-126^{\circ} \mathrm{C}$.

${ }^{1} \mathrm{H}-\mathrm{NMR}\left(500 \mathrm{MHz}, \mathrm{CDCl}_{3}\right) \delta: 3.91(3 \mathrm{H}, \mathrm{s}), 6.99(2 \mathrm{H}, \mathrm{d}, J=9.1 \mathrm{~Hz}), 7.91(1 \mathrm{H}, \mathrm{dd}, J=9.1,2.3 \mathrm{~Hz}), 7.96(2 \mathrm{H}, \mathrm{d}, J$ $=9.1 \mathrm{~Hz}), 8.09-8.11(2 \mathrm{H}, \mathrm{m}), 9.42(1 \mathrm{H}, \mathrm{s})$.

${ }^{13} \mathrm{C}-\mathrm{NMR}\left(126 \mathrm{MHz}, \mathrm{CDCl}_{3}\right) \delta: 55.8,114.3,122.7,125.0,128.0,130.8,133.4,134.9,136.0,149.9,154.0,158.3$, 163.7, 175.8 .

IR: $1647.21 \mathrm{~cm}^{-1}(\mathrm{C}=\mathrm{O})$

HRMS (FAB) $m / z$ Calcd for $\mathrm{C}_{16} \mathrm{H}_{12} \mathrm{ClN}_{2} \mathrm{O}_{2}(\mathrm{M}+\mathrm{H})^{+}: 299.0587$, Found: 229.0585.

According to the general procedure B, 5b was synthesized from pre-5b: Methylmagnesium bromide in THF (1.5 $\mathrm{mL}, 1.5 \mathrm{mmol})$ was added to a solution of pre-5b $(333 \mathrm{mg}, 1.11 \mathrm{mmol})$ in THF $(8 \mathrm{~mL})$. The solution was stirred fo $2.5 \mathrm{~h}$ at rt to afford $\mathbf{5 b}$ (192 $\mathrm{mg}, 55 \%)$.

Mp: $145-146^{\circ} \mathrm{C}$.

${ }^{1} \mathrm{H}-\mathrm{NMR}\left(500 \mathrm{MHz}, \mathrm{CDCl}_{3}\right) \delta: 2.09(3 \mathrm{H}, \mathrm{s}), 3.80(3 \mathrm{H}, \mathrm{s}), 6.01(1 \mathrm{H}, \mathrm{s}), 6.87(2 \mathrm{H}, \mathrm{d}, J=9.1 \mathrm{~Hz}), 7.31(2 \mathrm{H}, \mathrm{d}, J=8.5$ $\mathrm{Hz}), 7.73(1 \mathrm{H}, \mathrm{dd}, J=9.1,2.3 \mathrm{~Hz}), 7.80(1 \mathrm{H}, \mathrm{d}, J=2.3 \mathrm{~Hz}), 8.00(1 \mathrm{H}, \mathrm{d}, J=8.5 \mathrm{~Hz}), 9.32(1 \mathrm{H}, \mathrm{s})$.

${ }^{13} \mathrm{C}-\mathrm{NMR}\left(126 \mathrm{MHz}, \mathrm{CDCl}_{3}\right) \delta$ : 29.0, 55.4, 75.4, 114.2, 122.1, 125.7, 127.6, 131.1, 133.1, 134.6, 137.0, 149.7, 152.6, 159.3, 172.1 .

IR: $3244.27 \mathrm{~cm}^{-1}(\mathrm{OH})$ 
HRMS (ESI) $m / z$ Calcd for $\mathrm{C}_{17} \mathrm{H}_{15} \mathrm{ClN}_{2} \mathrm{O}_{2} \mathrm{Na}(\mathrm{M}+\mathrm{Na})^{+}: 337.0720$, Found: 337.0704 .

RT: 14.05 (EtOH: $\left.\mathrm{H}_{2} \mathrm{O}=1: 1,1 \mathrm{~mL} / \mathrm{min}\right)$.

\subsubsection{Synthesis of 1-(6-methylquinazolin-4-yl)-1-(4-methoxyphenyl)ethan-1-ol (5c)}

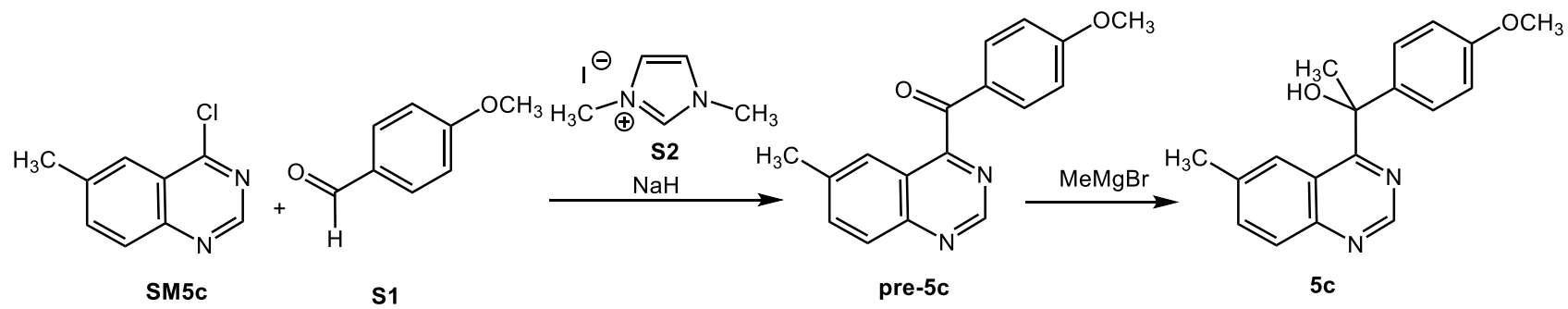

According to the general procedure A, pre-5c was synthesized: $\mathbf{S 1}(320 \mu \mathrm{L}, 2.64 \mathrm{mmol})$ and sodium hydride (131 $\mathrm{mg}, 5.44 \mathbf{m m o l}$ ) were added to a solution of 4-chloro-6-methylquinazoline $\mathbf{S M 5 \mathbf { c } ^ { 4 }}$ (423 $\mathrm{mg}, 2.37 \mathrm{mmol}$ ) and $\mathbf{S 2}$ (80.3 $\mathrm{mg}, 0.359 \mathrm{mmol})$ in THF $(15 \mathrm{~mL})$ at $0{ }^{\circ} \mathrm{C}$. The mixture was refluxed for $3.5 \mathrm{~h}$ to afford compound pre-5c $(357 \mathrm{mg}$, $54 \%)$.

Mp: $109-110^{\circ} \mathrm{C}$.

${ }^{1} \mathrm{H}-\mathrm{NMR}\left(500 \mathrm{MHz}, \mathrm{CDCl}_{3}\right) \delta: 2.52(3 \mathrm{H}, \mathrm{s}), 3.90(3 \mathrm{H}, \mathrm{s}), 6.98(2 \mathrm{H}, \mathrm{d}, J=9.1 \mathrm{~Hz}), 7.80-7.81(2 \mathrm{H}, \mathrm{m}), 7.94(2 \mathrm{H}, \mathrm{d}$, $J=9.1 \mathrm{~Hz}), 8.05(1 \mathrm{H}, \mathrm{d}, J=9.1 \mathrm{~Hz}), 9.35(1 \mathrm{H}, \mathrm{s})$.

${ }^{13} \mathrm{C}-\mathrm{NMR}\left(126 \mathrm{MHz}, \mathrm{CDCl}_{3}\right) \delta: 22.0,55.8,114.2,122.2,124.5,128.3,128.7,133.3,137.1,139.2,145.0,153.3$, 164.0, 164.9, 192.0.

IR: $1653.00 \mathrm{~cm}^{-1}(\mathrm{C}=\mathrm{O})$.

According to the general procedure B, $\mathbf{5 c}$ was synthesized from pre-5c: Methylmagnesium bromide in THF ( $820 \mu \mathrm{L}$, $0.820 \mathrm{mmol})$ was added to a solution of pre-5c $(226 \mathrm{mg}, 0.812 \mathrm{mmol})$ in THF $(10 \mathrm{~mL})$. The solution was stirred for $3 \mathrm{~h}$ at rt to afford $\mathbf{5 c}(172 \mathrm{mg}, 72 \%)$.

Mp: $97-99^{\circ} \mathrm{C}$.

${ }^{1} \mathrm{H}-\mathrm{NMR}\left(500 \mathrm{MHz}, \mathrm{CDCl}_{3}\right) \delta: 1.98(3 \mathrm{H}, \mathrm{s}), 2.22(3 \mathrm{H}, \mathrm{s}), 3.64(3 \mathrm{H}, \mathrm{s}), 6.44(1 \mathrm{H}, \mathrm{s}), 6.72(2 \mathrm{H}, \mathrm{d}, J=9.1 \mathrm{~Hz}), 7.20$ $(2 \mathrm{H}, \mathrm{d}, J=8.5 \mathrm{~Hz}), 7.47-7.48(2 \mathrm{H}, \mathrm{m}), 7.81(1 \mathrm{H}, \mathrm{d}, J=9.1 \mathrm{~Hz}), 9.11(1 \mathrm{H}, \mathrm{s})$.

${ }^{13} \mathrm{C}-\mathrm{NMR}\left(126 \mathrm{MHz}, \mathrm{CDCl}_{3}\right) \delta: 22.2,28.6,55.4,74.8,114.0,121.4,125.4,127.8,129.1,133.4,135.8,137.6,149.8$, 151.6, 159.1, 171.8 .

IR: $3197.98 \mathrm{~cm}^{-1}(\mathrm{OH})$.

LRMS (FAB) $m / z$ Calcd for $\mathrm{C}_{18} \mathrm{H}_{19} \mathrm{~N}_{2} \mathrm{O}_{2}(\mathrm{M}+\mathrm{H})^{+}: 295$, Found 295.

RT: 12.00 (EtOH: $\left.\mathrm{H}_{2} \mathrm{O}=1: 1,1 \mathrm{~mL} / \mathrm{min}\right)$.

\subsubsection{Synthesis of 1-(6-methoxyquinazolin-4-yl)-1-(4-methoxyphenyl)ethan-1-ol (5d)}<smiles>COc1ccc(C(=O)c2cnc3ccc(OC)cc3c2C(=O)c2ccc(OC)cc2)cc1</smiles> 
According to the general procedure A, pre-5d was synthesized: S1 $(460 \mu \mathrm{L}, 3.81 \mathrm{mmol})$ and sodium hydride (125 $\mathrm{mg}, 5.21 \mathrm{mmol}$ ) were added to a solution of 4-chloro-6-methoxyquinazoline $\mathbf{S M 5 d ^ { 6 }}(622 \mathrm{mg}, 3.20 \mathrm{mmol}$ ) and $\mathbf{S 2}$ $(144 \mathrm{mg}, 0.641 \mathrm{mmol})$ in THF $(15 \mathrm{~mL})$ at $0{ }^{\circ} \mathrm{C}$. The mixture was refluxed for $4 \mathrm{~h}$ to afford compound pre-5d $(148$ $\mathrm{mg}, 16 \%)$.

Mp: $174-175^{\circ} \mathrm{C}$.

${ }^{1} \mathrm{H}-\mathrm{NMR}\left(\mathrm{CDCl}_{3}\right) \delta: 3.88(3 \mathrm{H}, \mathrm{s}), 3.90(3 \mathrm{H}, \mathrm{s}), 6.99(2 \mathrm{H}, \mathrm{d}, J=9.1 \mathrm{~Hz}), 7.32(1 \mathrm{H}, \mathrm{d}, J=2.8 \mathrm{~Hz}), 7.61(1 \mathrm{H}, \mathrm{dd}, J=$ 9.1, $2.8 \mathrm{~Hz}), 7.96(2 \mathrm{H}, \mathrm{d}, J=9.1 \mathrm{~Hz}), 8.05(1 \mathrm{H}, \mathrm{d}, J=9.6 \mathrm{~Hz}), 9.30(1 \mathrm{H}, \mathrm{s})$.

${ }^{13} \mathrm{C}-\mathrm{NMR}\left(\mathrm{CDCl}_{3}\right) \delta: 55.8,55.9,102.4,114.2,123.3,128.2,128.4,130.5,133.4,148.1,151.9,159.1,162.2,164.9$, 192.0.

IR: $1653.00 \mathrm{~cm}^{-1}(\mathrm{C}=\mathrm{O})$.

According to the general procedure B, 5d was synthesized from pre-5d: Methylmagnesium bromide in THF (470 $\mu \mathrm{L}, 0.470 \mathrm{mmol})$ was added to a solution of pre-5d $(226 \mathrm{mg}, 0.812 \mathrm{mmol})$ in THF $(10 \mathrm{~mL})$. The solution was stirred for $4 \mathrm{~h}$ at $\mathrm{rt}$. The products were purified by column chromatography $(n$-hexane: dichloromethane: ethyl acetate $=10$ : 20: 1) to afford $\mathbf{5 d}(117 \mathrm{mg}, 82 \%)$.

Mp: $108-109^{\circ} \mathrm{C}$.

${ }^{1} \mathrm{H}-\mathrm{NMR}\left(500 \mathrm{MHz}, \mathrm{CDCl}_{3}\right) \delta: 2.08(3 \mathrm{H}, \mathrm{s}), 3.58(3 \mathrm{H}, \mathrm{s}), 3.77(3 \mathrm{H}, \mathrm{s}), 6.51(1 \mathrm{H}, \mathrm{s}), 6.85(2 \mathrm{H}, \mathrm{d}, J=8.5 \mathrm{~Hz}), 6.98$ $(1 \mathrm{H}, \mathrm{d}, J=2.8 \mathrm{~Hz}), 7.34(2 \mathrm{H}, \mathrm{d}, J=8.5 \mathrm{~Hz}), 7.41(1 \mathrm{H}, \mathrm{dd}, J=9.1,2.8 \mathrm{~Hz}), 7.92(1 \mathrm{H}, \mathrm{d}, J=9.6 \mathrm{~Hz}), 9.20(1 \mathrm{H}, \mathrm{s})$. ${ }^{13} \mathrm{C}-\mathrm{NMR}\left(126 \mathrm{MHz}, \mathrm{CDCl}_{3}\right) \delta: 28.1,55.4,55.5,74.7,104.0,114.7,122.3,126.5,128.0,130.7,137.6,147.4,150.5$, $157.7,159.2,170.7$.

IR: $3346.50 \mathrm{~cm}^{-1}(\mathrm{OH})$.

HRMS (EI) $m / z$ Calcd for $\mathrm{C}_{18} \mathrm{H}_{18} \mathrm{~N}_{2} \mathrm{O}_{3} \mathrm{M}^{+}: 310.1317$, Found: 310.1318 .

RT: $16.72\left(\mathrm{EtOH}: \mathrm{H}_{2} \mathrm{O}=1: 1,0.5 \mathrm{~mL} / \mathrm{min}\right)$.

\subsubsection{Synthesis of 1-(7-fluoroquinazolin-4-yl)-1-(4-methoxyphenyl)ethan-1-ol (6a)}

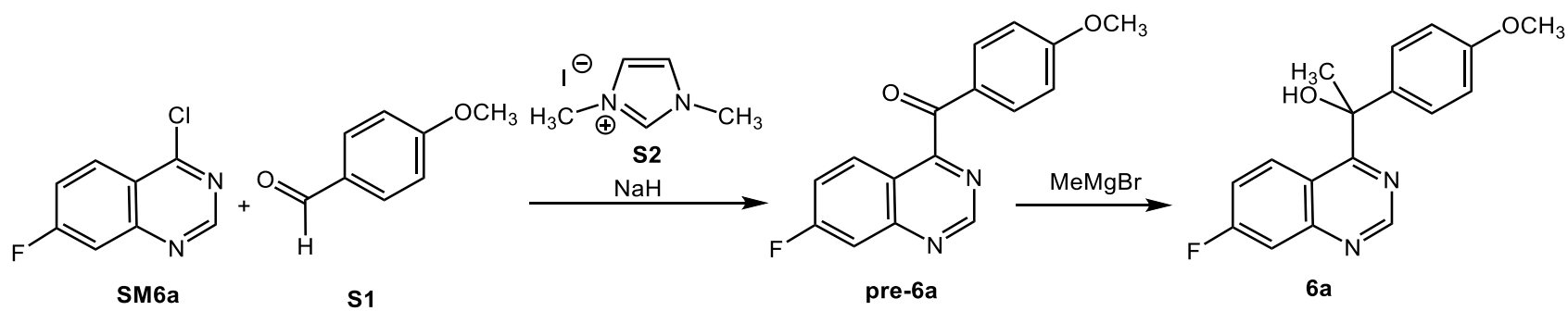

According to the general procedure A, pre-6a was synthesized: $\mathbf{S 1}(0.4 \mathrm{~mL}, 3.24 \mathrm{mmol})$ and sodium hydride (244 $\mathrm{mg}, 5.08 \mathrm{mmol}$ ) were added to a solution of 4-chloro-7-fluoroquinazoline SM6a ${ }^{4,7}$ (444 mg, $2.43 \mathrm{mmol}$ ) and 1,3dimethylimidazolium iodide $\mathbf{S 2}(125 \mathrm{mg}, 0.557 \mathrm{mmol})$ in THF $(15 \mathrm{~mL})$ and DMF $(5 \mathrm{~mL})$ at $0{ }^{\circ} \mathrm{C}$. The mixture was refluxed for $1.5 \mathrm{~h}$ to afford compound pre-6a (570 mg, 2.02mmol, $83 \%$ ).

Mp: $177-179^{\circ} \mathrm{C}$.

${ }^{1} \mathrm{H}-\mathrm{NMR}\left(300 \mathrm{MHz}, \mathrm{CDCl}_{3}\right) \delta: 3.90(3 \mathrm{H}, \mathrm{s}), 6.98(2 \mathrm{H}, \mathrm{d}, J=8.9 \mathrm{~Hz}), 7.40-7.46(1 \mathrm{H}, \mathrm{m}), 7.76(1 \mathrm{H}, \mathrm{dd}, J=4.7,2.5$ $\mathrm{Hz}), 7.96(2 \mathrm{H}, \mathrm{d}, J=8.9 \mathrm{~Hz}), 8.12(1 \mathrm{H}, \mathrm{dd}, J=9.2,5.8 \mathrm{~Hz}), 9.39(1 \mathrm{H}, \mathrm{s})$.

${ }^{13} \mathrm{C}-\mathrm{NMR}\left(126 \mathrm{MHz}, \mathrm{CDCl}_{3}\right) \delta: 55.6,112.8(\mathrm{~d}, J=20.5 \mathrm{~Hz}), 114.1,119.4,119.4(\mathrm{~d}, J=25.5 \mathrm{~Hz}), 127.9,129.0$ (d, $J=10.8 \mathrm{~Hz}), 133.1,153.0$ (d, $J=13.8 \mathrm{~Hz}), 154.7,164.1$ (d, $J=4.5 \mathrm{~Hz}), 164.8,167.5,190.9$.

LRMS (FAB) $m / z$ Calcd for $\mathrm{C}_{16} \mathrm{H}_{12} \mathrm{FN}_{2} \mathrm{O}_{2}(\mathrm{M}+\mathrm{H})^{+}: 283$, Found:283. 
According to the general procedure B, 6a was synthesized from pre-6a: Methylmagnesium bromide in THF (500 $\mu \mathrm{L}, 0.460 \mathrm{mmol})$ was added to a solution of pre-6a $(61.1 \mathrm{mg}, 0.216 \mathrm{mmol})$ in THF $(10 \mathrm{~mL})$. The solution was stirred for $6 \mathrm{~h}$ at $0{ }^{\circ} \mathrm{C}$. The product was purified by column chromatography ( $n$-hexane: dichloromethane: ethylacetate $=10$ : 5: 2) to afford a compound $\mathbf{6 a}(57.6 \mathrm{mg}, 0.193 \mathrm{mmol}, 89 \%)$.

Mp: $158-159^{\circ} \mathrm{C}$.

${ }^{1} \mathrm{H}-\mathrm{NMR}\left(300 \mathrm{MHz}, \mathrm{CDCl}_{3}\right) \delta: 2.08(3 \mathrm{H}, \mathrm{s}), 3.78(3 \mathrm{H}, \mathrm{s}), 6.21(1 \mathrm{H}, \mathrm{s}), 6.84(2 \mathrm{H}, \mathrm{d}, J=8.9 \mathrm{~Hz}), 7.15(1 \mathrm{H}, \mathrm{ddd}, J=$ 9.4, 8.1, $2.7 \mathrm{~Hz}), 7.28(2 \mathrm{H}, \mathrm{d}, J=8.9 \mathrm{~Hz}), 7.65(1 \mathrm{H}, \mathrm{dd}, J=9.3,2.7 \mathrm{~Hz}), 7.83(1 \mathrm{H}, \mathrm{dd}, J=9.4,5.9 \mathrm{~Hz}), 9.29(1 \mathrm{H}, \mathrm{s})$. ${ }^{13} \mathrm{C}-\mathrm{NMR}\left(126 \mathrm{MHz}, \mathrm{CDCl}_{3}\right) \delta: 29.1,55.3,75.3,113.1,114.1,117.9(\mathrm{~d}, J=25.5 \mathrm{~Hz}), 118.7,127.5,129.6(\mathrm{~d}, J=$ $10.2 \mathrm{~Hz}), 137.4,153.1,153.3,159.1,164.9(\mathrm{~d}, J=259 \mathrm{~Hz}), 172.6$.

HRMS (ESI) $m / z$ Calcd for $\mathrm{C}_{17} \mathrm{H}_{15} \mathrm{FN}_{2} \mathrm{O}_{2}(\mathrm{M}+\mathrm{Na})^{+}: 321.1015$, Found: 321.1023 .

RT: 11.02 (EtOH: $\left.\mathrm{H}_{2} \mathrm{O}=1: 1,1 \mathrm{~mL} / \mathrm{min}\right)$.

\subsubsection{Synthesis of 1-(7-chloroquinazolin-4-yl)-1-(4-methoxyphenyl)ethan-1-ol (6b)}

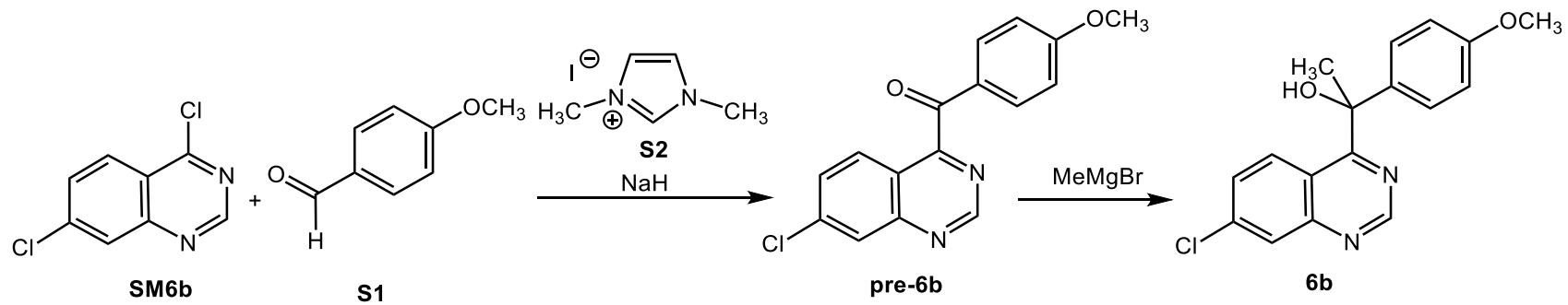

According to the general procedure A, pre-6b was synthesized: $\mathbf{S 1}(150 \mu \mathrm{L}, 1.17 \mathrm{mmol})$ and sodium hydride (59 $\mathrm{mg}$, $1.46 \mathrm{mmol}$ ) were added to a solution of 4,7-dichloroquinazoline $\mathbf{S M 6 b}^{7}$ (195 $\mathrm{mg}, 0.975 \mathrm{mmol}$ ) and 1,3dimethylimidazolium iodide $\mathbf{S 2}(22.4 \mathrm{mg}, 0.10 \mathrm{mmol}$ in THF $(10 \mathrm{~mL})$ at room temperature. The mixture was refluxed for $5 \mathrm{~h}$ to afford compound pre-6b (35.6 $\mathrm{mg}, 12 \%)$ as a colorless solid.

According to the general procedure B, $\mathbf{6 b}$ was synthesized from pre-6b: Methylmagnesium bromide in THF (150 $\mu \mathrm{L}, 0.15 \mathrm{mmol})$ was added to a solution of pre- $6 \mathbf{b}(34.4 \mathrm{mg}, 0.12 \mathrm{mmol})$ in THF $(5 \mathrm{~mL})$. The solution was stirred for $2.5 \mathrm{~h}$ at $0{ }^{\circ} \mathrm{C}$. The product was purified by column chromatography $(n$-hexane: dichloromethane: ethyl acetate $=$ 20: $10: 1)$ to afford a compound $\mathbf{6 b}(18.2 \mathrm{mg}, 50 \%)$ as a colorless solid.

Mp: $137-138^{\circ} \mathrm{C}$

${ }^{1} \mathrm{H}-\mathrm{NMR}\left(500 \mathrm{MHz}, \mathrm{CDCl}_{3}\right) \delta: 2.08(3 \mathrm{H}, \mathrm{s}), 3.78(3 \mathrm{H}, \mathrm{s}), 6.11(1 \mathrm{H}, \mathrm{s}), 6.85(2 \mathrm{H}, \mathrm{d}, J=8.5 \mathrm{~Hz}), 7.26-7.29(2 \mathrm{H}, \mathrm{m})$, $7.33(1 \mathrm{H}, \mathrm{dd}, J=9.4,2.0 \mathrm{~Hz}), 7.72(1 \mathrm{H}, \mathrm{d}, J=9.1 \mathrm{~Hz}), 8.05(1 \mathrm{H}, \mathrm{d}, J=2.3 \mathrm{~Hz}), 9.31(1 \mathrm{H}, \mathrm{s})$.

${ }^{13} \mathrm{C}-\mathrm{NMR}\left(126 \mathrm{MHz}, \mathrm{CDCl}_{3}\right) \delta: 29.0,55.4,75.2,114.2,119.9,127.7,128.1,128.4,128.6,137.3,139.9,152.0,153.3$, 159.2, 173.0.

IR: $3226.91 \mathrm{~cm}^{-1}(\mathrm{OH})$.

HRMS (ESI) $m / z$ Calcd for $\mathrm{C}_{17} \mathrm{H}_{14} \mathrm{ClN}_{2} \mathrm{O}_{2}(\mathrm{M}-\mathrm{H})^{-}: 313.0744$, Found: 313.0740.

RT: 18.49 (EtOH: $\mathrm{H}_{2} \mathrm{O}=1: 1,1 \mathrm{~mL} / \mathrm{min}$ ). 


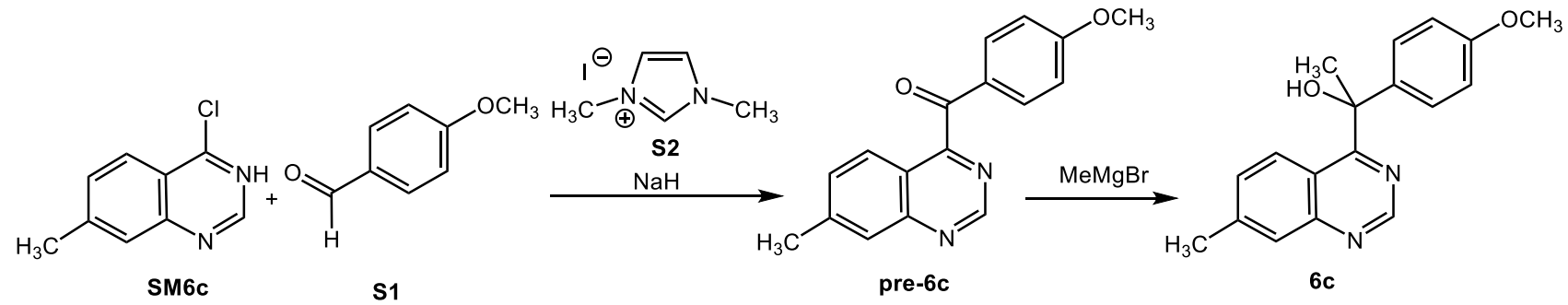

According to the general procedure A, pre-6c was synthesized: S1 (230 $\mu \mathrm{L}, 1.90 \mathrm{mmol})$ and sodium hydride (56.7 $\mathrm{mg}, 2.36 \mathrm{mmol}$ ) were added to a solution of 4-chloro-7-methylquinazoline SM6c $\mathbf{S}^{8}(278 \mathrm{mg}, 1.56 \mathrm{mmol})$ ) and 1,3dimethylimidazolium iodide $\mathbf{S 2}(74.0 \mathrm{mg}, 0.33 \mathrm{mmol})$ in THF $(5 \mathrm{~mL})$ at $0{ }^{\circ} \mathrm{C}$. The mixture was refluxed for $2.5 \mathrm{~h}$. The product was purified by silica gel column chromatography ( $n$-hexane: ethyl acetate $=3: 1)$ to afford compound pre-6c $(81.5 \mathrm{mg}, 19 \%)$ as a colorless solid.

M.p. $198-200{ }^{\circ} \mathrm{C}$.

${ }^{1} \mathrm{H}-\mathrm{NMR}\left(500 \mathrm{MHz}, \mathrm{CDCl}_{3}\right) \delta: 2.62(3 \mathrm{H}, \mathrm{s}), 3.89(3 \mathrm{H}, \mathrm{s}), 6.97(2 \mathrm{H}, \mathrm{d}, J=9.1 \mathrm{~Hz}), 7.48(1 \mathrm{H}, \mathrm{dd}, J=8.5,1.1 \mathrm{~Hz})$, 7.92-7.94 (4H, m), $9.36(1 \mathrm{H}, \mathrm{s})$.

${ }^{13} \mathrm{C}-\mathrm{NMR}\left(126 \mathrm{MHz}, \mathrm{CDCl}_{3}\right) \delta: 22.4,55.7,114.2,129.4,125.6,128.0,128.4,131.1,133.2,145.9,151.6,154.1$, 164.2, 164.7, 191.7.

IR: $1654.92 \mathrm{~cm}^{-1}(\mathrm{C}=\mathrm{O})$.

According to the general procedure B, $6 \mathbf{c}$ was synthesized from pre-6c: Methylmagnesium bromide in THF ( $240 \mu \mathrm{L}$, $0.240 \mathrm{mmol})$ was added to a solution of pre-6c $(64.8 \mathrm{mg}, 0.233 \mathrm{mmol})$ in THF $(15 \mathrm{~mL})$. The solution was stirred for $3 \mathrm{~h}$ at room temperature. The product was purified by column chromatography ( $n$-hexane: dichloromethane: ethyl acetate $=20: 10: 1)$ to afford a compound $\mathbf{6 c}(39.7 \mathrm{mg}, 58 \%)$ as a colorless solid.

M.p. $149-150{ }^{\circ} \mathrm{C}$.

${ }^{1} \mathrm{H}-\mathrm{NMR}\left(500 \mathrm{MHz}, \mathrm{CDCl}_{3}\right) \delta: 2.08(3 \mathrm{H}, \mathrm{s}), 2.51(3 \mathrm{H}, \mathrm{s}), 3.78(3 \mathrm{H}, \mathrm{s}), 6.55(1 \mathrm{H}, \mathrm{s}), 6.84(2 \mathrm{H}, \mathrm{d}, J=8.5 \mathrm{~Hz}), 7.21$ $(1 \mathrm{H}, \mathrm{dd}, J=8.8,1.4 \mathrm{~Hz}), 7.29(2 \mathrm{H}, \mathrm{d}, J=9.1 \mathrm{~Hz}), 7.60(1 \mathrm{H}, \mathrm{d}, J=8.5 \mathrm{~Hz}), 7.82(1 \mathrm{H}, \mathrm{s}), 9.27(1 \mathrm{H}, \mathrm{s})$.

${ }^{13} \mathrm{C}-\mathrm{NMR}\left(126 \mathrm{MHz}, \mathrm{CDCl}_{3}\right) \delta: 22.1,28.6,55.4,74.7,114.1,119.5,126.2,127.3,127.9,128.3,129.8,137.6,144.7$, 152.4, 159.1, 172.3.

IR: $3170.97 \mathrm{~cm}^{-1}(\mathrm{OH})$.

HRMS (ESI) $m / z$ Calcd for $\mathrm{C}_{18} \mathrm{H}_{19} \mathrm{~N}_{2} \mathrm{O}_{2}(\mathrm{M}+\mathrm{H})^{+}: 295.1447$, Found: 295.1439 .

RT: 9.43 (EtOH: $\left.\mathrm{H}_{2} \mathrm{O}=1: 1,1 \mathrm{~mL} / \mathrm{min}\right)$.

\subsubsection{Synthesis of 1-(7-methoxyquinazolin-4-yl)-1-(4-methoxyphenyl)ethan-1-ol (6d)}<smiles>COc1ccc(C(=O)c2ncnc3cc(C(C)(C)C)ccc23)cc1</smiles>

According to the general procedure A, pre-6d was synthesized: S1 $(350 \mu \mathrm{L} 2.90 \mathrm{mmol})$ and sodium hydride (123 $\mathrm{mg}, 5.13 \mathrm{mmol}$ ) were added to a solution of 4-chloro-7-methoxyquinazoline $\mathbf{S M 6 d}^{9}$ (462 mg, $2.59 \mathrm{mmol}$ ) and 1,3- 
dimethylimidazolium iodide $\mathbf{S 2}(120 \mathrm{mg}, 0.535 \mathrm{mmol})$ in THF $(15 \mathrm{~mL})$ at $0{ }^{\circ} \mathrm{C}$. The mixture was refluxed for $2 \mathrm{~h}$ to afford compound pre-6d $(88.7 \mathrm{mg}, 12 \%)$ as a colorless solid.

M.p. $195-197^{\circ} \mathrm{C}$.

${ }^{1} \mathrm{H}-\mathrm{NMR}\left(500 \mathrm{MHz}, \mathrm{CDCl}_{3}\right) \delta: 3.89(3 \mathrm{H}, \mathrm{s}), 4.01(3 \mathrm{H}, \mathrm{s}), 6.97(2 \mathrm{H}, \mathrm{d}, J=9.1 \mathrm{~Hz}), 7.25(1 \mathrm{H}, \mathrm{d}, J=2.3 \mathrm{~Hz}), 7.40$ $(1 \mathrm{H}, \mathrm{d}, J=2.3 \mathrm{~Hz}), 7.94(3 \mathrm{H}, \mathrm{dd}, J=9.1,1.1 \mathrm{~Hz}), 9.30(1 \mathrm{H}, \mathrm{s})$.

${ }^{13} \mathrm{C}-\mathrm{NMR}\left(126 \mathrm{MHz}, \mathrm{CDCl}_{3}\right) \delta: 55.8,56.0,106.4,114.2,117.7,122.3,127.4,128.4,133.3,153.9,154.6,163.5$, 164.6, 164.8, 191.8 .

IR: $1653.00 \mathrm{~cm}^{-1}(\mathrm{C}=\mathrm{O})$.

According to the general procedure B, $6 \mathbf{d}$ was synthesized from pre-6d: Methylmagnesium bromide in THF (180 $\mu \mathrm{L}, 0.180 \mathrm{mmol})$ was added to a solution of pre-6d $(51.8 \mathrm{mg}, 0.176 \mathrm{mmol})$ in THF $(15 \mathrm{~mL})$. The solution was stirred for $3 \mathrm{~h}$ at room temperature. The product was purified by column chromatography ( $n$-hexane: dichloromethane: ethyl acetate $=10: 60: 1)$ to afford a compound $\mathbf{6 d}(39.3 \mathrm{mg}, 72 \%)$ as a colorless solid.

M.p. $136-139^{\circ} \mathrm{C}$.

${ }^{1} \mathrm{H}-\mathrm{NMR}\left(500 \mathrm{MHz}, \mathrm{CDCl}_{3}\right) \delta: 2.07(3 \mathrm{H}, \mathrm{s}), 3.78(3 \mathrm{H}, \mathrm{s}), 3.92(3 \mathrm{H}, \mathrm{s}), 6.55(1 \mathrm{H}, \mathrm{s}), 6.84(2 \mathrm{H}, \mathrm{d}, J=8.5 \mathrm{~Hz}), 6.99$ $(1 \mathrm{H}, \mathrm{dd}, J=9.4,2.6 \mathrm{~Hz}), 7.27-7.32(3 \mathrm{H}, \mathrm{m}), 7.61(1 \mathrm{H}, \mathrm{d}, J=9.1 \mathrm{~Hz}), 9.21(1 \mathrm{H}, \mathrm{s})$.

${ }^{13} \mathrm{C}-\mathrm{NMR}\left(126 \mathrm{MHz}, \mathrm{CDCl}_{3}\right) \delta: 28.8,55.4,55.9,74.7,107.0,114.1,120.6,127.8,127.9,137.7,152.9,153.9,159.1$, 163.4, 171.6.

IR: $3078.39 \mathrm{~cm}^{-1}(\mathrm{OH})$.

HRMS(EI) $m / z$ Calcd for $\mathrm{C}_{18} \mathrm{H}_{18} \mathrm{~N}_{2} \mathrm{O}_{3}(\mathrm{M}+)^{+}: 310.1317$, Found: 310.1318 .

RT: 17.35 (EtOH: $\left.\mathrm{H}_{2} \mathrm{O}=1: 1,0.5 \mathrm{~mL} / \mathrm{min}\right)$.

\subsubsection{Synthesis of 1-(8-fluoroquinazolin-4-yl)-1-(4-methoxyphenyl)ethan-1-ol (7a)}

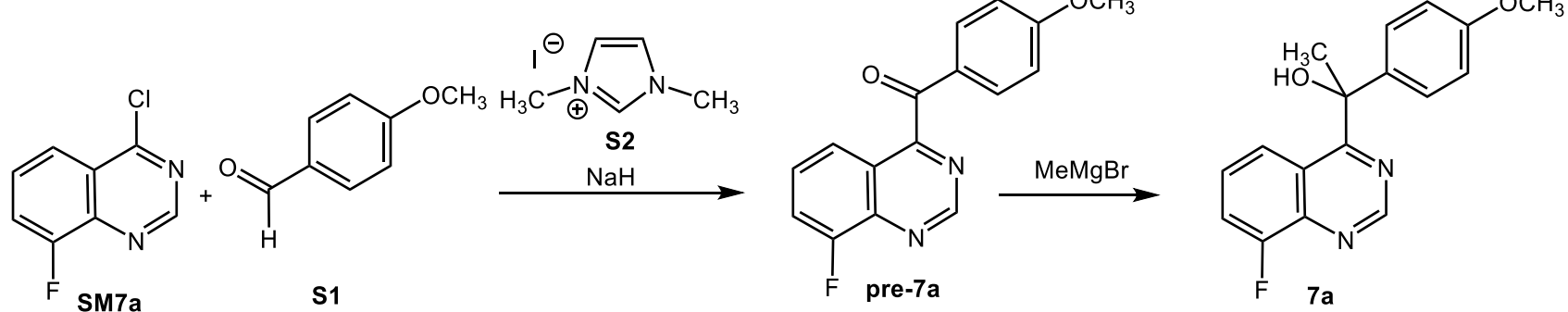

According to the general procedure A, pre-7a was synthesized: S1 $(300 \mu \mathrm{L}, 2.43 \mathrm{mmol})$ and sodium hydride (119 $\mathrm{mg}, 2.48 \mathrm{mmol}$ ) were added to a solution of 4-chloro-8-fluoroquinazoline $\mathbf{S M 7 \mathbf { a } ^ { 7 }}$ (338 $\mathrm{mg}, 0.185 \mathrm{mmol}$ ) and 1,3dimethylimidazolium iodide $\mathbf{S 2}(45.5 \mathrm{mg}, 0.203 \mathrm{mmol})$ in THF $(5 \mathrm{~mL})$ at $0{ }^{\circ} \mathrm{C}$. The mixture was refluxed for $1.5 \mathrm{~h}$ to afford compound pre-7a (302 $\mathrm{mg}, 1.07 \mathrm{mmol}, 56 \%)$.

Mp: $149-150^{\circ} \mathrm{C}$.

${ }^{1} \mathrm{H}-\mathrm{NMR}\left(500 \mathrm{MHz}, \mathrm{CDCl}_{3}\right) \delta: 3.90(3 \mathrm{H}, \mathrm{s}), 6.98(2 \mathrm{H}, \mathrm{d}, J=8.9 \mathrm{~Hz}), 7.59-7.70(2 \mathrm{H}, \mathrm{m}), 7.88(1 \mathrm{H}, \mathrm{d}, J=8.0 \mathrm{~Hz})$, $7.94(2 \mathrm{H}, \mathrm{d}, J=8.9 \mathrm{~Hz}), 9.48(1 \mathrm{H}, \mathrm{s})$.

${ }^{13} \mathrm{C}-\mathrm{NMR}\left(126 \mathrm{MHz}, \mathrm{CDCl}_{3}\right) \delta: 55.7,114.2,118.5(\mathrm{~d}, J=18.1 \mathrm{~Hz}), 121.8(\mathrm{~d}, J=5.4 \mathrm{~Hz}), 123.3,125.7,127.9$, $128.5(\mathrm{~d}, J=7.4 \mathrm{~Hz}), 133.2,154.0,157.3(\mathrm{~d}, J=262 \mathrm{~Hz}), 164.5(\mathrm{~d}, J=2.8 \mathrm{~Hz}), 164.9,190.8$.

According to the general procedure B, 7a was synthesized from pre-7a: Methylmagnesium bromide in THF $(2.2 \mathrm{~mL}$, $2.02 \mathrm{mmol})$ was added to a solution of pre-7a $(251 \mathrm{mg}, 0.890 \mathrm{mmol})$ in THF $(10 \mathrm{~mL})$. The solution was stirred for 
$6 \mathrm{~h}$ at $0{ }^{\circ} \mathrm{C}$ to afford a compound $7 \mathbf{a}(125 \mathrm{mg}, 0.419 \mathrm{mmol}, 47 \%)$ with starting material pre-7a $(14.0 \mathrm{mg}, 0.05 \mathrm{mmol}$, $5 \%)$.

Mp: $102-103^{\circ} \mathrm{C}$.

${ }^{1} \mathrm{H}-\mathrm{NMR}\left(500 \mathrm{MHz}, \mathrm{CDCl}_{3}\right) \delta$ : $9.40(1 \mathrm{H}, \mathrm{s}), 7.47-7.56(2 \mathrm{H}, \mathrm{m}), 7.32-7.38(1 \mathrm{H}, \mathrm{m}), 7.29(2 \mathrm{H}, \mathrm{d}, J=8.9 \mathrm{~Hz}), 6.85$ $(2 \mathrm{H}, \mathrm{d}, J=8.9 \mathrm{~Hz}), 6.21(1 \mathrm{H}, \mathrm{s}), 3.79(3 \mathrm{H}, \mathrm{s}), 2.10(3 \mathrm{H}, \mathrm{s})$.

${ }^{13} \mathrm{C}-\mathrm{NMR}\left(126 \mathrm{MHz}, \mathrm{CDCl}_{3}\right) \delta: 28.8,55.2,75.3,114.0,117.3(\mathrm{~d}, J=10.9 \mathrm{~Hz}), 122.4(\mathrm{~d}, J=3.0 \mathrm{~Hz}), 122.7,127.1$ (d, $J=4.8 \mathrm{~Hz}), 127.5,137.1,141.6(\mathrm{~d}, J=7.3 \mathrm{~Hz}), 152.3,157.5$ (d, $J=156 \mathrm{~Hz}), 159.0,172.7$.

HRMS (ESI) $m / z$ Calcd for $\mathrm{C}_{17} \mathrm{H}_{15} \mathrm{FN}_{2} \mathrm{O}_{2} \mathrm{Na}(\mathrm{M}+\mathrm{Na})^{+} ; 321.1015$, Found: 321.1001 .

RT: 7.53 (EtOH: $\left.\mathrm{H}_{2} \mathrm{O}=1: 1,1 \mathrm{~mL} / \mathrm{min}\right)$.

\subsubsection{Synthesis of 1-(8-chloroquinazolin-4-yl)-1-(4-methoxyphenyl)ethan-1-ol (7b)}

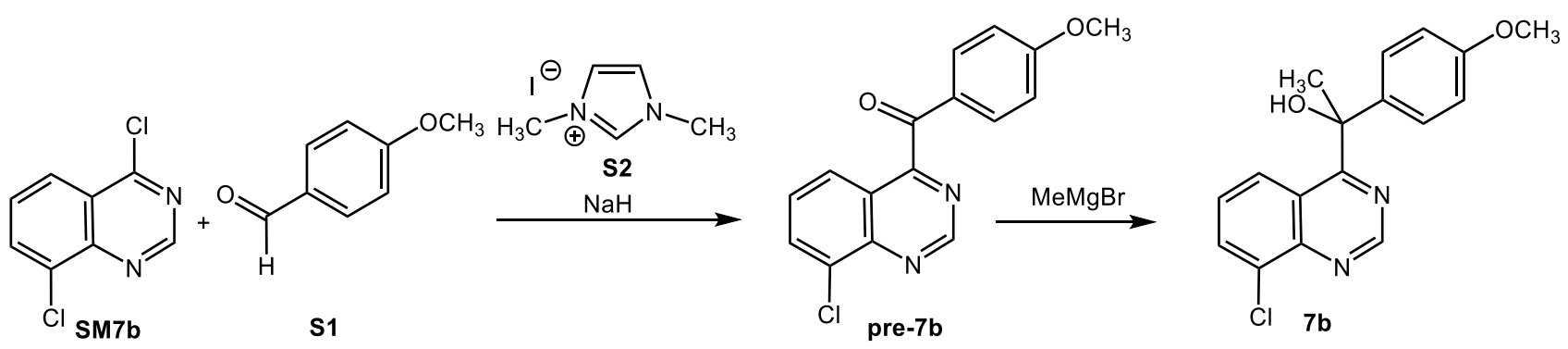

According to the general procedure A, pre-7b was synthesized: S1 $(132 \mu \mathrm{L}, 1.03 \mathrm{mmol})$ and sodium hydride $(52 \mathrm{mg}$, $1.29 \mathrm{mmol})$ were added to a solution of 4,8-dichloroquinazoline $\mathbf{S M 7 \mathbf { b } ^ { 5 }}(172 \mathrm{mg}, 0.86 \mathrm{mmol})$ and 1,3 dimethylimidazolium iodide $\mathbf{S 2}(19 \mathrm{mg}, 0.086 \mathrm{mmol})$ in THF $(10 \mathrm{~mL})$ at $0{ }^{\circ} \mathrm{C}$. The mixture was refluxed for $5 \mathrm{~h}$ to afford compound pre-7b (179 mg, 70\%).

According to the general procedure B, $7 \mathbf{b}$ was synthesized from pre-7b: Methylmagnesium bromide in THF (500 $\mu \mathrm{L}, 0.5 \mathrm{mmol})$ was added to a solution of pre-7b $(98.9 \mathrm{mg}, 0.331 \mathrm{mmol})$ in THF $(5 \mathrm{~mL})$. The mixture was stirred at $\mathrm{rt}$ for $2.5 \mathrm{~h}$. The product was purified by silica gel column chromatography ( $n$-hexane: dichloromethane: ethyl acetate $=20: 10: 1)$ to afford $7 \mathbf{b}(55.7 \mathrm{mg}, 54 \%)$ as a pale yellow solid.

M.p. $156-157^{\circ} \mathrm{C}$

${ }^{1} \mathrm{H}-\mathrm{NMR}\left(500 \mathrm{MHz}, \mathrm{CDCl}_{3}\right) \delta: 2.09(3 \mathrm{H}, \mathrm{s}), 3.79(3 \mathrm{H}, \mathrm{s}), 6.11(1 \mathrm{H}, \mathrm{s}), 6.84(2 \mathrm{H}, \mathrm{d}, J=9.6 \mathrm{~Hz}), 7.32-7.28(3 \mathrm{H}, \mathrm{m})$, $7.73(1 \mathrm{H}, \mathrm{d}, J=8.5 \mathrm{~Hz}), 7.90(1 \mathrm{H}, \mathrm{d}, J=7.4 \mathrm{~Hz}), 9.45(1 \mathrm{H}, \mathrm{s})$.

${ }^{13} \mathrm{C}-\mathrm{NMR}\left(126 \mathrm{MHz}, \mathrm{CDCl}_{3}\right) \delta: 29.1,55.4,75.3,114.2,122.8,125.7,127.4,127.7,133.5,133.9,137.4,147.98$, 152.8, 159.4, 173.6.

IR: $3290.56 \mathrm{~cm}^{-1}(\mathrm{OH})$.

HRMS(ESI) $m / z$ Calcd for $\mathrm{C}_{17} \mathrm{H}_{15} \mathrm{ClN}_{2} \mathrm{O}_{2} \mathrm{Na}(\mathrm{M}+\mathrm{Na})^{+}: 337.0720$, Found: 337.0708 .

RT: 11.59 (EtOH: $\mathrm{H}_{2} \mathrm{O}=1: 1,1 \mathrm{~mL} / \mathrm{min}$ ). 

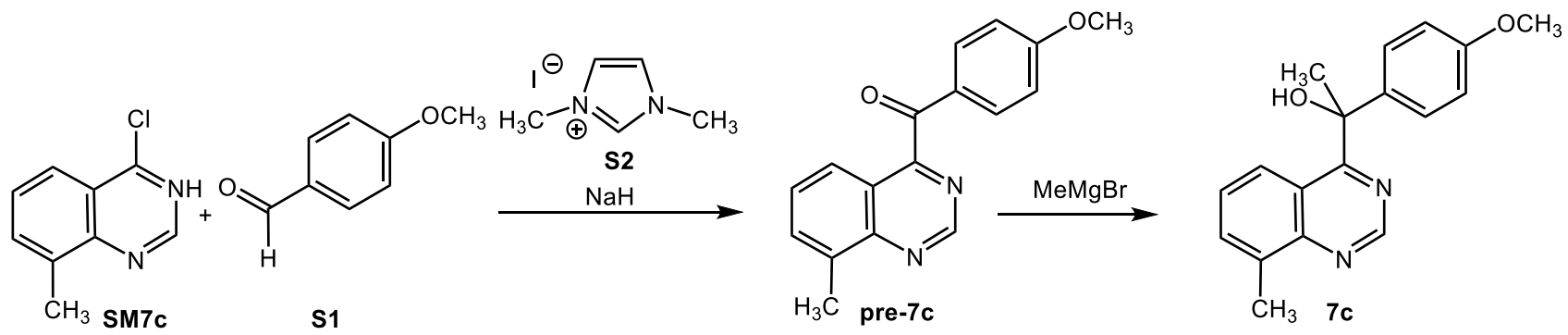

According to the general procedure A, pre-7c was synthesized: $\mathbf{S} 1(470 \mu \mathrm{L}, 3.88 \mathrm{mmol})$ and sodium hydride (122 $\mathrm{mg}, 5.07 \mathrm{mmol})$ were added to a solution of 4-chloro-8-methylquinazoline $\mathbf{S M 7 \mathbf { c } ^ { 1 0 }}(628 \mathrm{mg}, 3.23 \mathrm{mmol})$ and 1,3dimethylimidazolium iodide $\mathbf{S 2}(128 \mathrm{mg}, 0.570 \mathrm{mmol})$ in THF $(8 \mathrm{~mL})$ at $0{ }^{\circ} \mathrm{C}$. The mixture was refluxed for $2.5 \mathrm{~h}$ to afford compound pre-7c (227 mg, 25\%).

M.p. $130-133{ }^{\circ} \mathrm{C}$

${ }^{1} \mathrm{H}-\mathrm{NMR}\left(500 \mathrm{MHz}, \mathrm{CDCl}_{3}\right) \delta: 2.84(3 \mathrm{H}, \mathrm{s}), 3.89(3 \mathrm{H}, \mathrm{s}), 6.96(2 \mathrm{H}, \mathrm{d}, J=9.1 \mathrm{~Hz}), 7.53(1 \mathrm{H}, \mathrm{t}, J=7.7 \mathrm{~Hz}), 7.81$ $(1 \mathrm{H}, \mathrm{d}, J=6.8 \mathrm{~Hz}), 7.86(1 \mathrm{H}, \mathrm{d}, J=8.5 \mathrm{~Hz}), 7.92(2 \mathrm{H}, \mathrm{d}, J=9.1 \mathrm{~Hz}), 9.44(1 \mathrm{H}, \mathrm{s})$.

${ }^{13} \mathrm{C}-\mathrm{NMR}\left(126 \mathrm{MHz}, \mathrm{CDCl}_{3}\right) \delta: 17.5,55.7,114.2,122.1,123.7,128.3,128.4,133.2,134.5,137.4,150.4,153.1,164.8$, 171.8, 192.0.

IR: $1651.07 \mathrm{~cm}^{-1}(\mathrm{C}=\mathrm{O})$.

According to the general procedure B, 7c was synthesized from pre-7c: Methylmagnesium bromide in THF (700 $\mu \mathrm{L}$, $0.700 \mathrm{mmol})$ was added to a solution of pre-7c $(195 \mathrm{mg}, 0.700 \mathrm{mmol})$ in THF $(10 \mathrm{~mL})$. The reaction mixture was stirred for $3 \mathrm{~h}$ at room temperature. The product was purified by silica gel column chromatography ( $n$-hexane: dichloromethane: ethyl acetate $=20: 10: 1)$ to afford $7 \mathbf{c}(151 \mathrm{mg}, 73 \%)$ as a colorless solid.

M.p. $119-121^{\circ} \mathrm{C}$.

${ }^{1} \mathrm{H}-\mathrm{NMR}\left(500 \mathrm{MHz}, \mathrm{CDCl}_{3}\right) \delta: 2.08(3 \mathrm{H}, \mathrm{s}), 2.77(3 \mathrm{H}, \mathrm{s}), 3.76(3 \mathrm{H}, \mathrm{s}), 6.60(1 \mathrm{H}, \mathrm{s}), 6.83(2 \mathrm{H}, \mathrm{d}, J=8.5 \mathrm{~Hz}), 7.25-$ $7.29(3 \mathrm{H}, \mathrm{m}), 7.58(1 \mathrm{H}, \mathrm{d}, J=8.5 \mathrm{~Hz}), 7.62(1 \mathrm{H}, \mathrm{d}, J=7.4 \mathrm{~Hz}), 9.35(1 \mathrm{H}, \mathrm{s})$.

${ }^{13} \mathrm{C}-\mathrm{NMR}\left(126 \mathrm{MHz}, \mathrm{CDCl}_{3}\right) \delta: 18.1,28.7,55.4,74.9,114.1,121.4,124.4,127.0,127.8,133.5,137.7,137.7,150.3$, $151.2,159.1,172.7$

IR: $3261.63 \mathrm{~cm}^{-1}(\mathrm{OH})$.

HRMS(FAB) $m / z$ Calcd for $\mathrm{C}_{18} \mathrm{H}_{19} \mathrm{~N}_{2} \mathrm{O}_{2}(\mathrm{M}+\mathrm{H})^{+}:$295.1447, Found:295.1439.

RT: 11.79 (EtOH: $\mathrm{H}_{2} \mathrm{O}=1: 1,1 \mathrm{~mL} / \mathrm{min}$ ).

\subsubsection{Synthesis of 1-(8-methoxyquinazolin-4-yl)-1-(4-methoxyphenyl)ethan-1-ol (7d)}

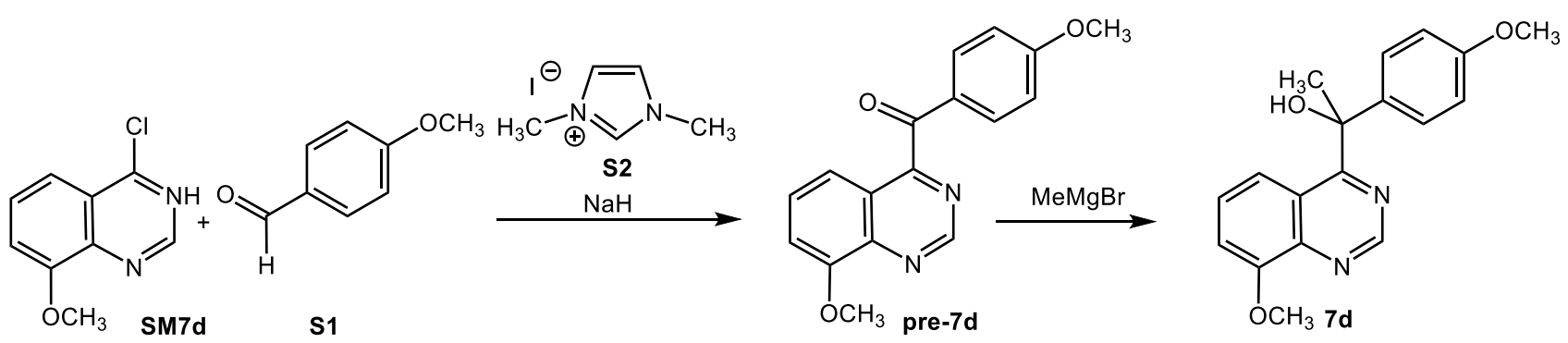

According to the general procedure A, pre-7d was synthesized: S1 $(600 \mu \mathrm{L}, 4.96 \mathrm{mmol})$ and sodium hydride (158 $\mathrm{mg}, 6.58 \mathrm{mmol}$ ) were added to a solution of 4-chloro-8-methoxyquinazoline $\mathbf{S M 7 \mathbf { d } ^ { 5 , 7 }}(753 \mathrm{mg}, 3.87 \mathrm{mmol})$ and 1,3dimethylimidazolium iodide $\mathbf{S 2}(151 \mathrm{mg}, 0.672 \mathrm{mmol})$ in THF $(10 \mathrm{~mL})$ at $0{ }^{\circ} \mathrm{C}$. The mixture was refluxed for $3 \mathrm{~h}$. 
The product was purified by silica gel column chromatography ( $n$-hexane: ethyl acetate $=3: 1)$ to afford compound pre-7d (261 $\mathrm{mg}, 23 \%)$ as a colorless solid.

M.p. $162-164{ }^{\circ} \mathrm{C}$.

${ }^{1} \mathrm{H}-\mathrm{NMR}\left(500 \mathrm{MHz}, \mathrm{CDCl}_{3}\right) \delta: 3.89(3 \mathrm{H}, \mathrm{s}), 4.14(3 \mathrm{H}, \mathrm{s}), 6.97(2 \mathrm{H}, \mathrm{d}, J=9.1 \mathrm{~Hz}), 7.26-7.30(1 \mathrm{H}, \mathrm{m}), 7.57(2 \mathrm{H}, \mathrm{t}, J$ $=2.8 \mathrm{~Hz}), 7.91(2 \mathrm{H}, \mathrm{d}, J=9.1 \mathrm{~Hz}), 9.43(1 \mathrm{H}, \mathrm{s})$.

${ }^{13} \mathrm{C}-\mathrm{NMR}\left(126 \mathrm{MHz}, \mathrm{CDCl}_{3}\right) \delta: 55.8,56.4,112.1,114.2,117.3,123.1,128.3,129.0,133.2,143.5,153.2,155.2,164.6$, 164.8, 191.7.

IR: $1651.07 \mathrm{~cm}^{-1}(\mathrm{C}=\mathrm{O})$.

According to the general procedure B, 7d was synthesized from pre-7d: Methylmagnesium bromide in THF (780 $\mu \mathrm{L}, 0.780 \mathrm{mmol})$ was added to a solution of pre-7d $(227 \mathrm{mg}, 0.771 \mathrm{mmol})$ in THF $(15 \mathrm{~mL})$. The reaction mixture was stirred for $3 \mathrm{~h}$ at room temperature. The product was purified by silica gel column chromatography ( $n$-hexane: ethyl acetate $=4: 1)$ to afford $7 \mathbf{d}(53.3 \mathrm{mg}, 22 \%)$ as a colorless solid.

M.p. $201-203^{\circ} \mathrm{C}$.

${ }^{1} \mathrm{H}-\mathrm{NMR}\left(500 \mathrm{MHz}, \mathrm{CDCl}_{3}\right) \delta: 2.09(3 \mathrm{H}, \mathrm{s}), 3.77(3 \mathrm{H}, \mathrm{s}), 4.06(3 \mathrm{H}, \mathrm{s}), 6.51(1 \mathrm{H}, \mathrm{s}), 6.84(2 \mathrm{H}, \mathrm{d}, J=8.5 \mathrm{~Hz}), 7.12$ $(1 \mathrm{H}, \mathrm{d}, J=7.4 \mathrm{~Hz}), 7.28-7.31(3 \mathrm{H}, \mathrm{m}), 9.36(1 \mathrm{H}, \mathrm{s})$.

${ }^{13} \mathrm{C}-\mathrm{NMR}\left(126 \mathrm{MHz}, \mathrm{CDCl}_{3}\right) \delta: 28.5,55.4,56.3,75.0,111.2,114.1,118.0,122.3,127.6,127.8,137.5,143.4,151.4$, $155.4,159.1,172.5$.

IR: $3259.70 \mathrm{~cm}^{-1}(\mathrm{OH})$.

HRMS(EI) $m / z$ Calcd for $\mathrm{C}_{18} \mathrm{H}_{18} \mathrm{~N}_{2} \mathrm{O}_{3}(\mathrm{M}+)^{+}: 310.1317$, Found: 310.1318 .

RT: 11.59 (EtOH: $\mathrm{H}_{2} \mathrm{O}=1: 1,0.5 \mathrm{~mL} / \mathrm{min}$ ).

\subsection{Synthesis of compound $2 \mathrm{~b}$ and 7a-o (Compounds in Table 2)}

\subsubsection{Synthesis of 1-(2-bromoquinazolin-4-yl)-1-(4-methoxyphenyl)ethan-1-ol (3b)}

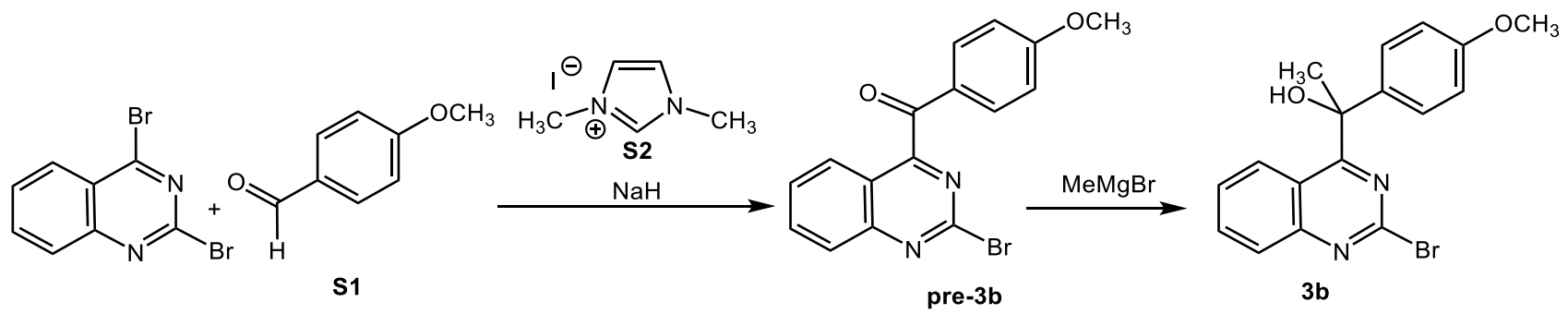

According to the general procedure A, pre-3b was synthesized: S1 $(600 \mu \mathrm{L}, 4.96 \mathrm{mmol})$ and sodium hydride ( 86.0 $\mathrm{mg}, 3.58 \mathrm{mmol})$ were added to a solution of 2,4-dibromoquinazoline ${ }^{11}(676 \mathrm{mg}, 2.35 \mathrm{mmol})$ and 1,3dimethylimidazolium iodide $\mathbf{S 2}(104 \mathrm{mg}, 0.466 \mathrm{mmol})$ in THF $(15 \mathrm{~mL})$ and DMF $(2 \mathrm{~mL})$ at $0{ }^{\circ} \mathrm{C}$. The mixture was stirred for $13 \mathrm{~h}$. The product was purified by silica gel column chromatography $(n$-hexane: ethyl acetate $=5: 1)$ to afford compound pre-3b (226 mg, 28\%) as a yellow solid.

Mp: $148-151^{\circ} \mathrm{C}$.

${ }^{1} \mathrm{H}-\mathrm{NMR}\left(500 \mathrm{MHz}, \mathrm{CDCl}_{3}\right) \delta: 3.92(3 \mathrm{H}, \mathrm{s}), 6.98(2 \mathrm{H}, \mathrm{d}, J=9.1 \mathrm{~Hz}), 7.66(1 \mathrm{H}, \mathrm{t}, J=7.7 \mathrm{~Hz}), 7.93(2 \mathrm{H}, \mathrm{d}, J=9.1$ $\mathrm{Hz}), 8.00(2 \mathrm{H}, \mathrm{t}, J=3.7 \mathrm{~Hz}), 8.08(1 \mathrm{H}, \mathrm{d}, J=7.9 \mathrm{~Hz})$.

${ }^{13} \mathrm{C}-\mathrm{NMR}\left(126 \mathrm{MHz}, \mathrm{CDCl}_{3}\right) \delta: 55.8,114.4,120.9,126.5,127.8,128.3,129.0,133.4,135.9,148.1,153.2,165.1$, 167.4, 189.7 .

IR: $1654.92 \mathrm{~cm}^{-1}(\mathrm{C}=\mathrm{O})$. 
FAB-MS: $m / z(\mathrm{M}+\mathrm{H})^{+}: 343$.

According to the general procedure B, $\mathbf{3 b}$ was synthesized from pre-3b: Methylmagnesium bromide in THF (330 $\mu \mathrm{L}, 0.330 \mathrm{mmol})$ was added to a solution of pre-3b $(76.3 \mathrm{mg}, 0.222 \mathrm{mmol})$ in THF $(10 \mathrm{~mL})$. The reaction mixture was stirred for $3 \mathrm{~h}$ at room temperature. The product was purified by silica gel column chromatography ( $n$-hexane: dichloromethane: ethyl acetate $=20: 10: 1)$ to afford $\mathbf{3 b}(523.6 \mathrm{mg}, 30 \%)$ as a colorless solid.

Mp: $126-128^{\circ} \mathrm{C}$.

${ }^{1} \mathrm{H}-\mathrm{NMR}\left(500 \mathrm{MHz}, \mathrm{CDCl}_{3}\right) \delta: 2.09(3 \mathrm{H}, \mathrm{s}), 3.78(3 \mathrm{H}, \mathrm{s}), 5.57(1 \mathrm{H}, \mathrm{s}), 6.85(2 \mathrm{H}, \mathrm{d}, J=9.1 \mathrm{~Hz}), 7.32(2 \mathrm{H}, \mathrm{d}, J=9.1$ $\mathrm{Hz}), 7.39(1 \mathrm{H}, \mathrm{t}, J=7.9 \mathrm{~Hz}), 7.79(2 \mathrm{H}, \mathrm{t}, J=8.5 \mathrm{~Hz}), 7.98(1 \mathrm{H}, \mathrm{d}, J=7.9 \mathrm{~Hz})$.

${ }^{13} \mathrm{C}-\mathrm{NMR}\left(126 \mathrm{MHz}, \mathrm{CDCl}_{3}\right) \delta: 29.1,55.3,75.7,114.1,120.1,127.1,127.6,127.7,128.5,134.5,136.8,146.4,153.2$, 159.1, 175.9.

IR: $3412.08 \mathrm{~cm}^{-1}(\mathrm{OH})$.

HRMS(EI) $m / z$ Calcd for $\mathrm{C}_{17} \mathrm{H}_{15} \mathrm{BrN}_{2} \mathrm{O}_{2}(\mathrm{M})^{+}: 358.0317$, Found: 358.0334 .

RT: 5.91 (EtOH: $\left.\mathrm{H}_{2} \mathrm{O}=1: 1,1 \mathrm{~mL} / \mathrm{min}\right)$.

\subsubsection{Synthesis of 1-(2-aminoquinazolin-4-yl)-1-(4-methoxyphenyl)ethan-1-ol (8a)}

A solution of 3a $(169.2 \mathrm{mg}, 0.029 \mathrm{mmol})$ in ethanol $(25 \mathrm{~mL})$ saturated with ammonia was stirred in a sealed tube at $135^{\circ} \mathrm{C}$. After cooling, ethanol was evaporated off and the product was extracted with chloroform. The organic layer was washed with brine, dried over $\mathrm{MgSO}_{4}$, filtered, and evaporated. The residue was purified by silica gel column chromatography (chloroform: methanol $=95: 5$ ) to afford compound $\mathbf{8 a}$ (88.8 mg, 56\%).

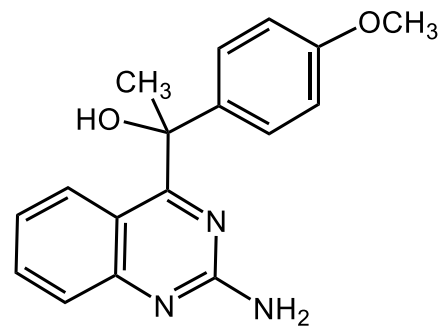
Mp: $209-211^{\circ} \mathrm{C}$.

${ }^{1} \mathrm{H}-\mathrm{NMR}\left(500 \mathrm{MHz}, \mathrm{CDCl}_{3}\right) \delta: 2.06(3 \mathrm{H}, \mathrm{s}), 3.78(3 \mathrm{H}, \mathrm{s}), 5.25(2 \mathrm{H}, \mathrm{s}), 6.31(1 \mathrm{H}, \mathrm{s}), 6.85(2 \mathrm{H}, \mathrm{d}, J=9.1 \mathrm{~Hz}), 6.99$ $7.02(1 \mathrm{H}, \mathrm{m}), 7.31(2 \mathrm{H}, \mathrm{d}, J=9.1 \mathrm{~Hz}), 7.47(1 \mathrm{H}, \mathrm{d}, J=7.4 \mathrm{~Hz}), 7.59-7.57(2 \mathrm{H}, \mathrm{m})$.

${ }^{13} \mathrm{C}-\mathrm{NMR}\left(126 \mathrm{MHz}, \mathrm{CDCl}_{3}\right) \delta: 28.2,55.4,74.6,114.1,116.4,122.9,126.3,127.1,127.8,133.9,137.3,153.5,157.4$, 159.1, 174.9.

IR: $3381.21 \mathrm{~cm}^{-1}(\mathrm{OH})$.

HRMS(FAB) m/z Calcd for $\mathrm{C}_{17} \mathrm{H}_{18} \mathrm{~N}_{3} \mathrm{O}_{2}(\mathrm{M}+\mathrm{H})^{+}:$296.1399, Found: 296.1406 .

RT: 6.48 (EtOH: $\left.\mathrm{H}_{2} \mathrm{O}=1: 1,1 \mathrm{~mL} / \mathrm{min}\right)$.

\subsubsection{Synthesis of 1-(2-methylaminoquinazolin-4-yl)-1-(4-methoxyphenyl)ethan-1-ol (8b)}

Methylamine $40 \%$ methanol solution ( $860 \mu \mathrm{L}, 0.593 \mathrm{mmol}$ )was added to a solution of 3a ( $42.8 \mathrm{mg}, 0.136 \mathrm{mmol})$ in 1,4-dioxane $(2 \mathrm{~mL})$. The mixture was stirred for 18 $\mathrm{h}$ at room temperature, and was poured into ice-water. The product was extracted with ethyl acetate. The organic layer was washed with brine, dried over $\mathrm{MgSO}_{4}$, filtered, and evaporated. The residue was purified by silica gel column chromatography (chloroform) to afford compound $\mathbf{8 b}(12.3 \mathrm{mg}, 29 \%)$ as a yellow<smiles>COc1ccc(C(C)(O)c2nc(N(C)C)nc3ccccc23)cc1</smiles>
solid.

Mp: $149-152{ }^{\circ} \mathrm{C}$.

${ }^{1} \mathrm{H}-\mathrm{NMR}\left(500 \mathrm{MHz}, \mathrm{CDCl}_{3}\right) \delta: 2.05(3 \mathrm{H}, \mathrm{s}), 3.18(3 \mathrm{H}, \mathrm{d}, J=5.1 \mathrm{~Hz}), 3.78(3 \mathrm{H}, \mathrm{s}), 5.38(1 \mathrm{H}, \mathrm{br} \mathrm{s}), 6.45(1 \mathrm{H}, \mathrm{br} \mathrm{s})$, 
$6.84(2 \mathrm{H}, \mathrm{d}, J=8.5 \mathrm{~Hz}), 6.91-6.95(1 \mathrm{H}, \mathrm{m}), 7.31(2 \mathrm{H}, \mathrm{d}, J=8.5 \mathrm{~Hz}), 7.42(1 \mathrm{H}, \mathrm{d}, J=7.9 \mathrm{~Hz}), 7.53(1 \mathrm{H}, \mathrm{dt}, J=8.3$, $3.5 \mathrm{~Hz}), 7.62(1 \mathrm{H}, \mathrm{d}, J=8.5 \mathrm{~Hz})$.

${ }^{13} \mathrm{C}-\mathrm{NMR}\left(126 \mathrm{MHz}, \mathrm{CDCl}_{3}\right) \delta: 28.2,28.5,55.3,74.3,113.9,116.0,122.0,126.5,127.0,127.3,133.5,137.3,153.8$, $157.4,159.0,173.8$.

IR: $3261.63 \mathrm{~cm}^{-1}(\mathrm{OH})$.

HRMS(FAB) $m / z$ Calcd for $\mathrm{C}_{18} \mathrm{H}_{20} \mathrm{~N}_{3} \mathrm{O}_{2}(\mathrm{M}+\mathrm{H})^{+}: 310.1556$, Found: 310.1548 .

RT: 9.24 (EtOH: $\left.\mathrm{H}_{2} \mathrm{O}=1: 1,1 \mathrm{~mL} / \mathrm{min}\right)$.

\subsubsection{Synthesis of 1-(2-(aziridin-1-yl)quinazolin-4-yl)-1-(4-methoxyphenyl)ethanol (8c)}

Under an atmosphere of argon, aziridine $(0.022 \mathrm{~mL}, 0.425 \mathrm{mmol})$ and trimethylamine $(0.057 \mathrm{~mL}, 0.409 \mathrm{mmol})$ was added to a solution of $3 \mathbf{a}(0.124 \mathrm{~g}, 0.395$ mmol) in 1,4-dioxane $(5 \mathrm{~mL})$. The reaction was stirred for $24 \mathrm{~h}$ at $60{ }^{\circ} \mathrm{C}$, and then poured into an ice-water. The product was extracted with ethyl acetate and washed with brine. After being dried over sodium sulfate, the organic layer was concentrated under reduced pressure. The residue was purified by silica gel column chromatography ( $n$-hexane: ethyl acetate $=3: 1)$ to afford $\mathbf{8 c}$ as a yellow solid $(65.5$<smiles>COc1ccc(C(C)(O)c2nc(N3CC3)nc3ccccc23)cc1</smiles>
$\mathrm{mg}, 0.204 \mathrm{mmol}, 50 \%)$.

${ }^{1} \mathrm{H}-\mathrm{NMR}\left(500 \mathrm{MHz}, \mathrm{CDCl}_{3}\right) \delta$ : 7.97-7.99 (m, 1H), 7.79-7.82 (m, 2H), 7.37-7.40 (m, 1H), 7.31-7.34 (m, 2H), 6.85$6.88(\mathrm{~m}, 2 \mathrm{H}), 5.54(\mathrm{~s}, 1 \mathrm{H}), 3.79(\mathrm{~s}, 3 \mathrm{H}), 2.11(\mathrm{~s}, 3 \mathrm{H}), 1.82(\mathrm{~s}, 4 \mathrm{H})$.

LRMS (FAB) $m / z$ Calcd for $\mathrm{C}_{19} \mathrm{H}_{20} \mathrm{~N}_{3} \mathrm{O}_{2}(\mathrm{M}+\mathrm{H})^{+}: 322$, Found: 322 .

RT: 8.21 (EtOH: $\left.\mathrm{H}_{2} \mathrm{O}=1: 1,1 \mathrm{~mL} / \mathrm{min}\right)$.

\subsubsection{Synthesis of 1-(2-(azetidin-1-yl)quinazolin-4-yl)-1-(4-methoxyphenyl)ethanol (8d)}

Under an atmosphere of argon, azetidine hydrochloride $(62.0 \mathrm{mg}, 0.663 \mathrm{mmol})$ and trimethylamine $(0.2 \mathrm{~mL}, 1.43 \mathrm{mmol})$ was added to a solution of $\mathbf{3 a}(0.209 \mathrm{~g}, 0.663$ $\mathrm{mmol})$ in 1,4-dioxane $(5 \mathrm{~mL})$. The reaction was heated under reflux for $5 \mathrm{~h}$ with stirring, and then poured into an ice-water. The product was extracted with ethyl acetate and washed with brine. After being dried over sodium sulfate, the organic layer was concentrated under reduced pressure. The residue was purified by silica<smiles>COc1ccc(C(C)(O)c2nc(N3CCC3)nc3ccccc23)cc1</smiles>
gel column chromatography ( $n$-hexane: ethyl acetate $=3: 1$ ) to afford $\mathbf{8 d}$ as a yellow solid (91.9 mg, 0.274mmol, 41\%).

${ }^{1} \mathrm{H}-\mathrm{NMR}\left(500 \mathrm{MHz}, \mathrm{CDCl}_{3}\right) \delta: 7.62(\mathrm{~d}, J=8.6 \mathrm{~Hz}, 1 \mathrm{H}), 7.50-7.54(\mathrm{~m}, 1 \mathrm{H}), 7.40-7.42(\mathrm{~m}, 1 \mathrm{H}), 7.31(\mathrm{dd}, J=6.6,2.0$ $\mathrm{Hz}, 2 \mathrm{H}), 6.90-6.94(\mathrm{~m}, 1 \mathrm{H}), 6.85(\mathrm{dd}, J=6.6,2.0 \mathrm{~Hz}, 2 \mathrm{H}), 6.64(\mathrm{~d}, J=1.4 \mathrm{~Hz}, 1 \mathrm{H}), 4.36(\mathrm{t}, J=7.4 \mathrm{~Hz}, 4 \mathrm{H}), 3.79$ (s, $3 \mathrm{H}), 2.45-2.51(\mathrm{~m}, 2 \mathrm{H}), 2.05(\mathrm{~s}, 3 \mathrm{H})$

HRMS (FAB) $m / z$ calcd for $\mathrm{C}_{20} \mathrm{H}_{22} \mathrm{~N}_{3} \mathrm{O}_{2}(\mathrm{M}+\mathrm{H})^{+}: 336.1707$, found: 336.1709 .

RT: 15.28 (EtOH: $\mathrm{H}_{2} \mathrm{O}=1: 1,1 \mathrm{~mL} / \mathrm{min}$ ). 


\section{General procedure C}

Under an atmosphere of argon, pyrrolidine $(28 \mathrm{mg}, 0.4 \mathrm{mmol})$ was added to a solution of 3a $(62 \mathrm{mg}, 0.2 \mathrm{mmol})$ in 1,4-dioxane $(5 \mathrm{~mL})$. The reaction mixture was heated under reflux for $5 \mathrm{~h}$ with stirring, and then poured into an ice-water. The product was extracted with ethyl acetate and washed with brine. After being dried over sodium sulfate, the organic layer was concentrated under reduced pressure. The residue was<smiles>COc1ccc(C(C)(O)c2nc(N3CCCC3)nc3ccccc23)cc1</smiles>
purified by silica gel column chromatography ( $n$-hexane: ethyl acetate) to afford $\mathbf{8 e}(50.3 \mathrm{mg}, 72 \%)$.

${ }^{1} \mathrm{H}-\mathrm{NMR}\left(500 \mathrm{MHz}, \mathrm{CDCl}_{3}\right) \delta: 2.06(3 \mathrm{H}, \mathrm{s}), 2.07-2.10(4 \mathrm{H}, \mathrm{m}), 3.78-3.83(7 \mathrm{H}, \mathrm{m}), 6.79(1 \mathrm{H}, \mathrm{s}), 6.84(2 \mathrm{H}, \mathrm{d}, J=$ 8.5), 6.86-6.89 (1H, m), $7.33(2 \mathrm{H}, \mathrm{d}, J=8.5), 7.38(1 \mathrm{H}, \mathrm{d}, J=8.4), 7.48-7.52(1 \mathrm{H}, \mathrm{m}), 7.59(1 \mathrm{H}, \mathrm{d}, J=8.2)$.

HRMS(EI) $m / z$ Calcd for $\mathrm{C}_{21} \mathrm{H}_{23} \mathrm{~N}_{3} \mathrm{O}_{2}(\mathrm{M})^{+}: 349.1790$, Found: 349.1797 .

RT: 5.97 (EtOH: $\left.\mathrm{H}_{2} \mathrm{O}=7: 3,1 \mathrm{~mL} / \mathrm{min}\right)$.

\subsubsection{Synthesis of 1-(4-methoxyphenyl)-1-(2-(thiazolidine-3-yl)quinazolin-4-yl)ethan-1-ol (8f)}

According to the general procedure C, $\mathbf{8 f}(21 \mathrm{mg}, 29 \%)$ was synthesized from 3a and thiazolidine in the reaction for $12 \mathrm{~h}$.

${ }^{1} \mathrm{H}-\mathrm{NMR}\left(500 \mathrm{MHz}, \mathrm{CDCl}_{3}\right) \delta: 2.07(3 \mathrm{H}, \mathrm{s}), 3.21(2 \mathrm{H}, \mathrm{t}, J=6.2 \mathrm{~Hz}), 3.78(3 \mathrm{H}, \mathrm{s})$, $4.20(2 \mathrm{H}, \mathrm{t}, J=6.2 \mathrm{~Hz}), 4.98(2 \mathrm{H}, \mathrm{s}), 6.34(1 \mathrm{H}, \mathrm{s}), 6.85(2 \mathrm{H}, \mathrm{d}, J=9.1 \mathrm{~Hz}), 6.95-6.98$ $(1 \mathrm{H}, \mathrm{m}), 7.32(2 \mathrm{H}, \mathrm{d}, J=9.1 \mathrm{~Hz}), 7.46(1 \mathrm{H}, \mathrm{d}, J=8.5 \mathrm{~Hz}), 7.54-7.57(1 \mathrm{H}, \mathrm{m}), 7.64$ $(1 \mathrm{H}, \mathrm{d}, J=8.5 \mathrm{~Hz})$.

HRMS (EI) $m / z$ Calcd for $\mathrm{C}_{20} \mathrm{H}_{21} \mathrm{~N}_{3} \mathrm{O}_{2} \mathrm{~S}(\mathrm{M})^{+}:$367.1354, Found: 367.1359 .<smiles>COc1ccc(C(C)(O)c2nc(N3CCSC3)nc3ccccc23)cc1</smiles>

RT: 6.27 (EtOH: $\left.\mathrm{H}_{2} \mathrm{O}=7: 3,1 \mathrm{~mL} / \mathrm{min}\right)$.

\subsubsection{Synthesis of 1-(2-(2,5-dihydro-1H-pyrrol-1- yl)quinazolin-4-yl)-1-(4-methoxyphenyl)ethan-1-ol (8g)}

According to the general procedure C, $8 \mathbf{g}$ ( $46 \mathrm{mg}, 66 \%$ ) was synthesized from $\mathbf{3 a}$ and 2,5-dihydro- $1 H$-pyrrole. The reaction mixture was heated at $115^{\circ} \mathrm{C}$ for $1.5 \mathrm{~h}$ and then at $80{ }^{\circ} \mathrm{C}$ for $11 \mathrm{~h}$. The titled compound was eluted as the second fraction of the silica gel column chromatography, following the first fraction which contains $\mathbf{8 g}$.

${ }^{1} \mathrm{H}-\mathrm{NMR}\left(500 \mathrm{MHz}, \mathrm{CDCl}_{3}\right) \delta: 2.08(3 \mathrm{H}, \mathrm{s}), 3.79$ (3H, s), 4.59 (4H, br s), $6.02(2 \mathrm{H}$, s), $6.74(1 \mathrm{H}, \mathrm{s}), 6.85(2 \mathrm{H}, \mathrm{d}, J=3.0 \mathrm{~Hz}), 6.91-6.92(1 \mathrm{H}, \mathrm{m}), 7.34(2 \mathrm{H}, \mathrm{d}, J=9.1 \mathrm{~Hz})$,<smiles>COc1ccc(C(C)(O)c2nc(N3CC=CC3)nc3ccccc23)cc1</smiles>
$7.42(1 \mathrm{H}, \mathrm{d}, J=8.5 \mathrm{~Hz}), 7.52-7.55(1 \mathrm{H}, \mathrm{m}), 7.64(1 \mathrm{H}, \mathrm{d}, J=7.9 \mathrm{~Hz})$.

HRMS(FAB) $m / z$ Calcd for $\mathrm{C}_{21} \mathrm{H}_{22} \mathrm{~N}_{3} \mathrm{O}_{2}(\mathrm{M}+\mathrm{H})^{+}: 348.1712$, Found: 348.1729 .

RT: 5.51 (EtOH: $\mathrm{H}_{2} \mathrm{O}=7: 3,1 \mathrm{~mL} / \mathrm{min}$ ). 
The titled compound was obtained together with $\mathbf{8 g}$ as a minor product in the above described synthesis. It was eluted earlier than $\mathbf{8 g}$ in the chromatography.

${ }^{1} \mathrm{H}-\mathrm{NMR}\left(500 \mathrm{MHz}, \mathrm{CDCl}_{3}\right) \delta: 2.14(3 \mathrm{H}, \mathrm{s}), 3.79(3 \mathrm{H}, \mathrm{s}), 5.71(1 \mathrm{H}, \mathrm{s}), 6.44(2 \mathrm{H}, \mathrm{t}, J$ $=2.3 \mathrm{~Hz}), 6.87(2 \mathrm{H}, \mathrm{d}, J=9.1 \mathrm{~Hz}), 7.23-7.27(3 \mathrm{H}, \mathrm{m}), 7.36(2 \mathrm{H}, \mathrm{d}, J=8.5 \mathrm{~Hz}), 7.72-$ $7.75(2 \mathrm{H}, \mathrm{m}), 7.93(1 \mathrm{H}, \mathrm{d}, J=8.5 \mathrm{~Hz}), 8.01(2 \mathrm{H}, \mathrm{t}, J=2.3 \mathrm{~Hz})$.

HRMS (FAB) $m / z$ Calcd for $\mathrm{C}_{21} \mathrm{H}_{20} \mathrm{~N}_{3} \mathrm{O}_{2}(\mathrm{M}+\mathrm{H})^{+}: 346.1556$, Found: 346.1555 . RT: 7.84 (EtOH: $\left.\mathrm{H}_{2} \mathrm{O}=7: 3,1 \mathrm{~mL} / \mathrm{min}\right)$.

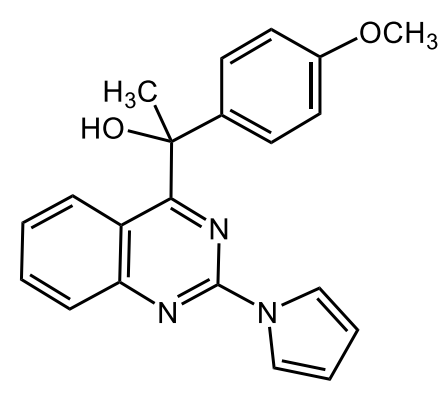

\subsubsection{Synthesis of 1-(2-(3,6-dihydropyridin-1(2H)-yl)quinazolin-4-yl)-1-(4-methoxyphenyl)ethan-1-ol (8i)}

According to the general procedure C, $\mathbf{8 i}(36.3 \mathrm{mg}, 51 \%)$ was synthesized from $\mathbf{3 a}$ and 1,2,3,6-tetrahydropyridine.

${ }^{1} \mathrm{H}-\mathrm{NMR}\left(500 \mathrm{MHz}, \mathrm{CDCl}_{3}\right) \delta: 2.07(3 \mathrm{H}, \mathrm{s}), 2.34-2.36(2 \mathrm{H}, \mathrm{m}), 3.79(3 \mathrm{H}, \mathrm{s}), 4.15$ $(2 \mathrm{H}, \mathrm{t}, J=5.7 \mathrm{~Hz}), 4.43-4.44(2 \mathrm{H}, \mathrm{m}), 5.86-5.89(1 \mathrm{H}, \mathrm{m}), 5.96-5.98(1 \mathrm{H}, \mathrm{m}), 6.50$ $(1 \mathrm{H}, \mathrm{s}), 6.85(2 \mathrm{H}, \mathrm{d}, J=9.1 \mathrm{~Hz}), 6.90-6.93(1 \mathrm{H}, \mathrm{m}), 7.33(2 \mathrm{H}, \mathrm{d}, J=9.1 \mathrm{~Hz}), 7.41$ $(1 \mathrm{H}, \mathrm{d}, J=8.5 \mathrm{~Hz}), 7.51-7.52(1 \mathrm{H}, \mathrm{m}), 7.60(1 \mathrm{H}, \mathrm{d}, J=8.5 \mathrm{~Hz})$.

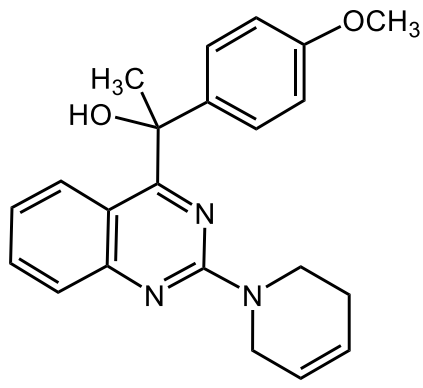
HRMS (FAB) $m / z$ Calcd for $\mathrm{C}_{22} \mathrm{H}_{24} \mathrm{~N}_{3} \mathrm{O}_{2}(\mathrm{M}+\mathrm{H})^{+}: 362.1869$, Found: 362.1854 .

RT: 7.08 (EtOH: $\left.\mathrm{H}_{2} \mathrm{O}=7: 3,1 \mathrm{~mL} / \mathrm{min}\right)$.

\subsubsection{Synthesis of 1-(4-methoxyphenyl)-1-(2-thiomorpholinoquinazolin-4-yl)ethan-1-ol (8j)}

According to the general procedure C, $\mathbf{8 j}$ (64.6 mg, 85\%) was synthesized from $\mathbf{3 a}$ and thiomorpholine in the reaction at reflux temperature for $16 \mathrm{~h}$.

${ }^{1} \mathrm{H}-\mathrm{NMR}\left(500 \mathrm{MHz}, \mathrm{CDCl}_{3}\right) \delta: 2.06(3 \mathrm{H}, \mathrm{s}), 2.77-2.78(2 \mathrm{H}, \mathrm{m}), 3.79(3 \mathrm{H}, \mathrm{s}), 4.35-$ $4.37(2 \mathrm{H}, \mathrm{m}), 6.23(1 \mathrm{H}, \mathrm{s}), 6.86(2 \mathrm{H}, \mathrm{d}, J=8.5 \mathrm{~Hz}), 6.94-6.95(1 \mathrm{H}, \mathrm{m}), 7.32(2 \mathrm{H}, \mathrm{d}$, $J=9.1 \mathrm{~Hz}), 7.44(1 \mathrm{H}, \mathrm{d}, J=8.5 \mathrm{~Hz}), 7.52-7.55(1 \mathrm{H}, \mathrm{m}), 7.58(1 \mathrm{H}, \mathrm{d}, J=8.5 \mathrm{~Hz})$. HRMS(EI) $m / z$ Calcd for $\mathrm{C}_{21} \mathrm{H}_{23} \mathrm{~N}_{3} \mathrm{O}_{2} \mathrm{~S}(\mathrm{M})^{+}:$381.1511, Found: 381.1507 . RT: 5.89 (EtOH: $\left.\mathrm{H}_{2} \mathrm{O}=7: 3,1 \mathrm{~mL} / \mathrm{min}\right)$.

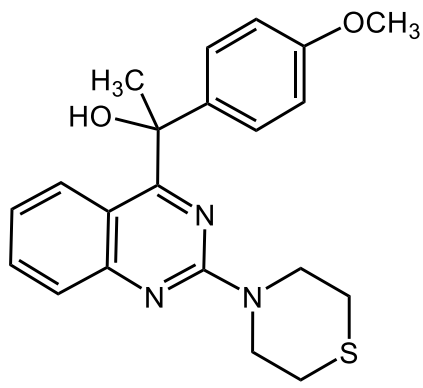

\subsubsection{Synthesis of 1-(2-(4-fluoropiperidin-1-yl)quinazolin-4-yl)-1-(4-methoxyphenyl)ethan-1-ol (8k)}

According to the general procedure C, 8k $(57.7 \mathrm{mg}, 76 \%)$ was synthesized from 3a and 4-fluoropiperidine hydrochloride (36 $\mathrm{mg}, 0.22 \mathrm{mmol}$ ) in the reaction using DBU $(0.3 \mathrm{mmol})$ as a base at reflux temperature for $18 \mathrm{~h}$.

${ }^{1} \mathrm{H}-\mathrm{NMR}\left(500 \mathrm{MHz}, \mathrm{CDCl}_{3}\right.$ ) $\delta:$ 2.01-2.03 (4H, m), 2.07 (3H, s), 3.79 (3H, s), 4.10$4.14(4 \mathrm{H}, \mathrm{m}), 4.90-5.03(1 \mathrm{H}, \mathrm{m}), 6.35(1 \mathrm{H}, \mathrm{s}), 6.86(2 \mathrm{H}, \mathrm{d}, J=9.1 \mathrm{~Hz}), 6.92-6.95(1 \mathrm{H}$, m), $7.33(2 \mathrm{H}, \mathrm{d}, J=9.1 \mathrm{~Hz}), 7.42(1 \mathrm{H}, \mathrm{d}, J=8.5 \mathrm{~Hz}), 7.52-7.54(1 \mathrm{H}, \mathrm{m}), 7.58(1 \mathrm{H}, \mathrm{d}$, $J=7.9 \mathrm{~Hz})$.

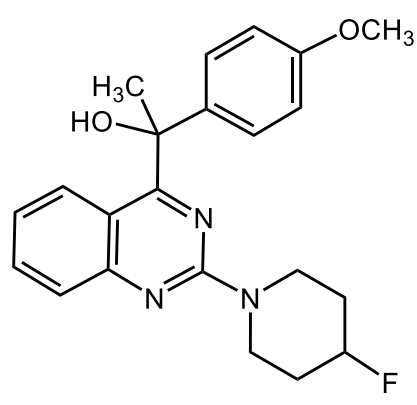

HRMS (EI) $m / z$ Calcd for $\mathrm{C}_{22} \mathrm{H}_{24} \mathrm{FN}_{3} \mathrm{O}_{2}(\mathrm{M})^{+}: 381.1853$, Found: 381.1848 .

RT: 10.97 (EtOH: $\mathrm{H}_{2} \mathrm{O}=7: 3,1 \mathrm{~mL} / \mathrm{min}$ ). 
According to the general procedure C, $\mathbf{8 f}(5.6 \mathrm{mg}, 7 \%)$ was synthesized from $\mathbf{3 a}$ and 4,4-difluoropiperidine in the reaction at reflux temperature for $16 \mathrm{~h}$.

${ }^{1} \mathrm{H}-\mathrm{NMR}\left(500 \mathrm{MHz}, \mathrm{CDCl}_{3}\right) \delta: 2.07$ (3H, s), 2.10-2.15 (4H, m), 3.79 (3H, s), 4.18$4.19(4 \mathrm{H}, \mathrm{m}), 6.17(1 \mathrm{H}, \mathrm{s}), 6.86(2 \mathrm{H}, \mathrm{d}, J=9.1 \mathrm{~Hz}), 6.95-6.99(1 \mathrm{H}, \mathrm{m}), 7.32(2 \mathrm{H}, \mathrm{d}$, $J=8.5 \mathrm{~Hz}), 7.46(1 \mathrm{H}, \mathrm{d}, J=7.9 \mathrm{~Hz}), 7.55-7.56(1 \mathrm{H}, \mathrm{m}), 7.60(1 \mathrm{H}, \mathrm{d}, J=8.5 \mathrm{~Hz})$. HRMS (EI) $m / z$ Calcd for $\mathrm{C}_{22} \mathrm{H}_{23} \mathrm{~F}_{2} \mathrm{~N}_{3} \mathrm{O}_{2}(\mathrm{M})^{+}: 399.1758$, Found: 399.1766 . RT: 6.49 (EtOH: $\left.\mathrm{H}_{2} \mathrm{O}=7: 3,1 \mathrm{~mL} / \mathrm{min}\right)$.

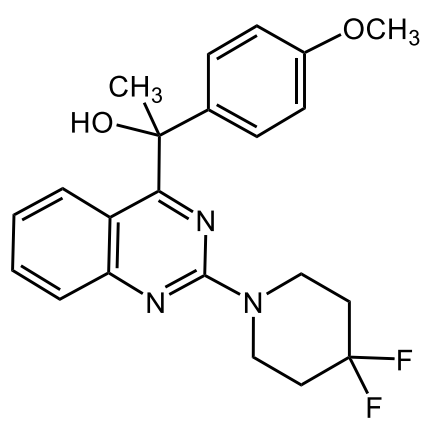

\subsubsection{Synthesis of 1-(2-(4-chloropiperidin-1-yl)quinazolin-4-yl)-1-(4-methoxyphenyl)ethan-1-ol (8m)}

According to the general procedure C, $\mathbf{8 m}(63.9 \mathrm{mg}, 80 \%)$ was synthesized from $\mathbf{3 a}$ and 4-chloropiperidine in the reaction at reflux temperature for $16 \mathrm{~h}$.

${ }^{1} \mathrm{H}-\mathrm{NMR}\left(500 \mathrm{MHz}, \mathrm{CDCl}_{3}\right) \delta: 1.99-2.02(1 \mathrm{H}, \mathrm{m}), 2.06(3 \mathrm{H}, \mathrm{s}), 2.23-2.25(2 \mathrm{H}, \mathrm{m})$, 2.77-2.78 (1H, m), $3.79(3 \mathrm{H}, \mathrm{s}), 3.86-3.91(2 \mathrm{H}, \mathrm{m}), 4.37-4.39(3 \mathrm{H}, \mathrm{m}), 6.31(1 \mathrm{H}, \mathrm{s})$, $6.86(2 \mathrm{H}, \mathrm{d}, J=8.5 \mathrm{~Hz}), 6.92-6.96(1 \mathrm{H}, \mathrm{m}), 7.32(2 \mathrm{H}, \mathrm{d}, J=9.1 \mathrm{~Hz}), 7.43(1 \mathrm{H}, \mathrm{d}, J=$ $8.5 \mathrm{~Hz}), 7.51-7.55(1 \mathrm{H}, \mathrm{m}), 7.58(1 \mathrm{H}, \mathrm{d}, J=7.4 \mathrm{~Hz})$.

HRMS (EI) $m / z$ Calcd for $\mathrm{C}_{22} \mathrm{H}_{24} \mathrm{ClN}_{3} \mathrm{O}_{2}(\mathrm{M})^{+}: 397.1557$, Found: 397.1561 .

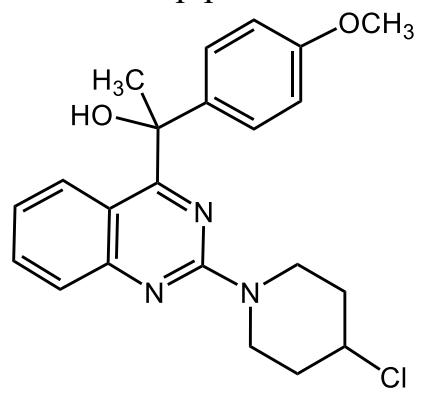

RT: 12.97 (EtOH: $\mathrm{H}_{2} \mathrm{O}=7: 3,1 \mathrm{~mL} / \mathrm{min}$ ).

\subsubsection{Synthesis of 1-(2-(4-hydroxypiperidin-1-yl)quinazolin-4-yl)-1-(4-methoxyphenyl)ethan-1-ol (8n)}

According to the general procedure C, 8n $(55.6 \mathrm{mg}, 73 \%)$ was synthesized from 3a and 4-hydroxypiperidine.

${ }^{1} \mathrm{H}-\mathrm{NMR}\left(500 \mathrm{MHz}, \mathrm{CDCl}_{3}\right) \delta: 1.65-1.67(2 \mathrm{H}, \mathrm{m}), 2.04-2.10(6 \mathrm{H}, \mathrm{m}), 3.50-3.55(2 \mathrm{H}$, m), $3.79(3 \mathrm{H}, \mathrm{s}), 4.01-4.06(1 \mathrm{H}, \mathrm{m}), 4.59-4.64(2 \mathrm{H}, \mathrm{m}), 6.41(1 \mathrm{H}, \mathrm{s}), 6.85(2 \mathrm{H}, \mathrm{d}, J$ $=7.4 \mathrm{~Hz}), 6.90-6.94(1 \mathrm{H}, \mathrm{m}), 7.33(2 \mathrm{H}, \mathrm{d}, J=8.5 \mathrm{~Hz}), 7.41(1 \mathrm{H}, \mathrm{t}, J=4.3 \mathrm{~Hz}), 7.50-$ $7.53(1 \mathrm{H}, \mathrm{m}), 7.58(1 \mathrm{H}, \mathrm{t}, J=4.3 \mathrm{~Hz})$.

HRMS (EI) $m / z$ Calcd for $\mathrm{C}_{22} \mathrm{H}_{25} \mathrm{~N}_{3} \mathrm{O}_{3}(\mathrm{M})^{+}: 379.1896$, Found: 379.1889 .

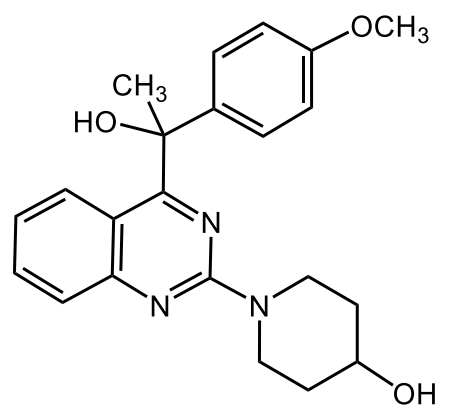

RT: 10.36 (EtOH: $\left.\mathrm{H}_{2} \mathrm{O}=1: 1,1 \mathrm{~mL} / \mathrm{min}\right)$.

\subsubsection{Synthesis of 1-(4-methoxyphenyl)-1-(2-(4-methoxypiperidin-1-yl)quinazolin-4-yl)ethan-1-ol (80)}

According to the general procedure C, 80 (44 mg, 56\%) was synthesized from 3a and 4-methoxypiperidine in the reaction at reflux temperature for $16 \mathrm{~h}$.

${ }^{1} \mathrm{H}-\mathrm{NMR}\left(500 \mathrm{MHz}, \mathrm{CDCl}_{3}\right) \delta$ : 1.68-1.71 (2H, m), 2.05-2.07 (5H, m), $3.44(3 \mathrm{H}$, s), 3.59-3.64 $(2 \mathrm{H}, \mathrm{m}), 3.79(3 \mathrm{H}, \mathrm{s}), 4.47-4.50(3 \mathrm{H}, \mathrm{m}), 4.47(1 \mathrm{H}, \mathrm{br} \mathrm{s}), 6.85(2 \mathrm{H}$, d, $J=8.5 \mathrm{~Hz}), 6.91(1 \mathrm{H}, \mathrm{t}, J=7.4 \mathrm{~Hz}), 7.32(2 \mathrm{H}, \mathrm{d}, J=9.1 \mathrm{~Hz}), 7.40(1 \mathrm{H}, \mathrm{d}, J=$ $8.5 \mathrm{~Hz}), 7.51(1 \mathrm{H}, \mathrm{t}, J=7.7 \mathrm{~Hz}), 7.57(1 \mathrm{H}, \mathrm{d}, J=7.9 \mathrm{~Hz})$. HRMS (EI) $m / z$ Calcd for $\mathrm{C}_{23} \mathrm{H}_{27} \mathrm{~N}_{3} \mathrm{O}_{3}(\mathrm{M})^{+}:$393.2052, Found: 393.2034.<smiles>COc1ccc(C(C)(O)c2nc(N3CCC(OC)CC3)nc3ccccc23)cc1</smiles>
RT: 4.84 (EtOH: $\left.\mathrm{H}_{2} \mathrm{O}=7: 3,1 \mathrm{~mL} / \mathrm{min}\right)$. 


\subsection{Synthesis of compound 9a-r (Compounds in Table 3)}

\subsubsection{Synthesis of 1-(4-methoxyphenyl)-1-(2-vinylquinazolin-4-yl)ethan-1-ol (9a)}

\section{General procedure D}

Under an atmosphere of argon, aqueous potassium carbonate $(2.0 \mathrm{M}, 0.5 \mathrm{~mL})$ was added to the mixture of $\mathbf{3 a}(62.4 \mathrm{mg}, 0.2 \mathrm{mmol})$, vinyboronic acid dibutyl ester (50 $\mu \mathrm{L}, 0.2 \mathrm{mmol}$ ), and $\mathrm{PdCl}_{2}(\mathrm{dppf})$ dichloromethane adduct (12.3 $\left.\mathrm{mg}, 0.015 \mathrm{mmol}\right)$ in 1,4-dioxane $(1.0 \mathrm{~mL})$. The mixture was refluxed for $3.5 \mathrm{~h}$, and then poured into ice water. The product was extracted with ethyl acetate. The organic layer was washed with brine, dried over $\mathrm{Na}_{2} \mathrm{SO}_{4}$, filtered, and evaporated. The residue was purified by

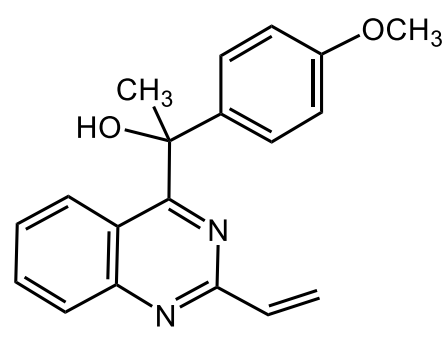
silica gel column chromatography ( $n$-hexane: ethyl acetate $=4: 1$ ) to afford $9 \mathbf{a}(53.8 \mathrm{mg}, 86 \%)$.

Mp: $121-123^{\circ} \mathrm{C}$.

${ }^{1} \mathrm{H}-\mathrm{NMR}\left(500 \mathrm{MHz}, \mathrm{CDCl}_{3}\right) \delta: 2.12(3 \mathrm{H}, \mathrm{d}, J=13.6 \mathrm{~Hz}), 3.80(3 \mathrm{H}, \mathrm{d}, J=13.6 \mathrm{~Hz}), 5.92(1 \mathrm{H}, \mathrm{dd}, J=10.5,1.4 \mathrm{~Hz})$, $6.73(1 \mathrm{H}, \mathrm{s}), 6.85-6.88(3 \mathrm{H}, \mathrm{m}), 7.09(1 \mathrm{H}, \mathrm{dd}, J=17.3,10.5 \mathrm{~Hz}), 7.29(1 \mathrm{H}, \mathrm{d}, J=4.0 \mathrm{~Hz}), 7.32(2 \mathrm{H}, \mathrm{d}, J=8.5 \mathrm{~Hz})$, $7.66(1 \mathrm{H}, \mathrm{d}, J=8.5 \mathrm{~Hz}), 7.73-7.77(1 \mathrm{H}, \mathrm{m}), 8.00(1 \mathrm{H}, \mathrm{d}, J=7.9 \mathrm{~Hz})$.

${ }^{13} \mathrm{C}-\mathrm{NMR}\left(126 \mathrm{MHz}, \mathrm{CDCl}_{3}\right) \delta: 28.4,55.2,74.7,114.0,119.9,124.6,126.6,126.9,127.8,129.3,133.5,136.3,137.4$, 151.5, 159.0, 172.3.

IR: $3350.35 \mathrm{~cm}^{-1}(\mathrm{OH})$.

LRMS (EI) $\mathrm{m} / z$ Calcd for $\mathrm{C}_{19} \mathrm{H}_{18} \mathrm{~N}_{2} \mathrm{O}_{2}(\mathrm{M})^{+}:$306, Found: 306.

LRMS (FAB) $m / z$ Calcd for $\mathrm{C}_{19} \mathrm{H}_{19} \mathrm{~N}_{2} \mathrm{O}_{2}(\mathrm{M}+\mathrm{H})^{+}:$307, Found: 307.

RT: 15.76 (EtOH: $\mathrm{H}_{2} \mathrm{O}=1: 1,1 \mathrm{~mL} / \mathrm{min}$ ).

\subsubsection{1-[2-(1-Propenyl)quinazoline-4-yl]-1-(4-methoxyphenyl)ethanol (9b)}

According to the general procedure D, $9 \mathbf{b}(58.2 \mathrm{mg}, 45 \%)$ was synthesized from 3a (72.3 mg, $0.229 \mathrm{mmol})$ and 1-propenylboroic acid $(29.7 \mathrm{mg}, 0.322$ $\mathrm{mmol}$ ), using $\mathrm{PdCl}_{2}$ (dppf) dichloromethane adduct (19.5 mg, $\left.0.026 \mathrm{mmol}\right)$ and aqueous potassium carbonate $(2.0 \mathrm{M}, 2.0 \mathrm{~mL})$ in 1,4-dioxane $(4.0 \mathrm{~mL})$. The reaction was conducted at reflux temperature for $20 \mathrm{~h}$.

Mp: $114-117^{\circ} \mathrm{C}$.

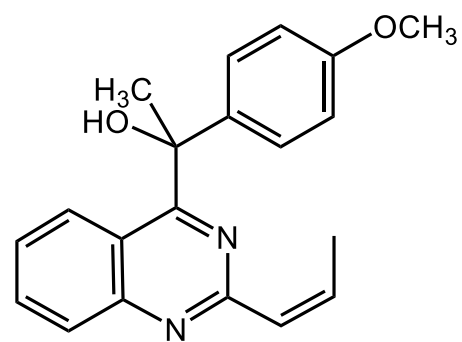

${ }^{1} \mathrm{H}-\mathrm{NMR}\left(300 \mathrm{MHz}, \mathrm{CDCl}_{3}\right) \delta: 2.10(3 \mathrm{H}, \mathrm{s}), 2.43(3 \mathrm{H}, \mathrm{dd}, J=7.3,1.8 \mathrm{~Hz}), 3.78(3 \mathrm{H}, \mathrm{s}), 6.35-6.47(1 \mathrm{H}, \mathrm{s}), 6.64$ $(1 \mathrm{H}, \mathrm{s}), 6.76-6.81(1 \mathrm{H}, \mathrm{m}), 6.85(2 \mathrm{H}, \mathrm{d}, J=8.7 \mathrm{~Hz}), 7.30-7.34(3 \mathrm{H}, \mathrm{m}), 7.65(1 \mathrm{H}, \mathrm{d}, J=4.6 \mathrm{~Hz}), 7.73(1 \mathrm{H}, \mathrm{ddd}, J=$ $8.2,6.9,1.2 \mathrm{~Hz}), 7.99(1 \mathrm{H}, \mathrm{d}, J=8.9 \mathrm{~Hz})$.

${ }^{13} \mathrm{C}-\mathrm{NMR}\left(126 \mathrm{MHz}, \mathrm{CDCl}_{3}\right) \delta: 18.5,28.4,55.2,74.7,113.9,119.5,126.3,126.5,127.8,129.0,130.7,133.3$, $137.4,138.2,151.8,157.8,159.0,172.0$.

HRMS (FAB) $m / z$ Calcd forC $\mathrm{C}_{20} \mathrm{H}_{21} \mathrm{~N}_{2} \mathrm{O}_{2}(\mathrm{M}+\mathrm{H})^{+}: 321.1603$, Found: 321.1603.

RT: 22.71 (EtOH: $\mathrm{H}_{2} \mathrm{O}=1: 1,1 \mathrm{~mL} / \mathrm{min}$ ).

\subsubsection{Synthesis of 1-(2-Cyclopropylquinazoline-4-yl)-1-(4-methoxyphenyl)ethanol (9c)}

According to the general procedure D, 9c (26.6 mg, 24\%) was synthesized from 3a (108 mg, $0.344 \mathrm{mmol})$ and 
cyclopropylboronic acid monohydrate (44.1 mg, $0.424 \mathrm{mmol})$, using $\mathrm{Pd}\left(\mathrm{PPh}_{3}\right)_{4}(22.3$ $\mathrm{mg}, 0.019 \mathrm{mmol})$ and potassium carbonate $(121 \mathrm{mg}, 0.923 \mathrm{mmol})$ in toluene $(4.0$ $\mathrm{mL}$ ). The reaction was conducted at reflux temperature for $34 \mathrm{~h}$. The product was purified by silica gel column chromatography ( $n$-hexane: dichloromethane: ethyl acetate $=10: 5: 1)$.

Mp: $119-120^{\circ} \mathrm{C}$.

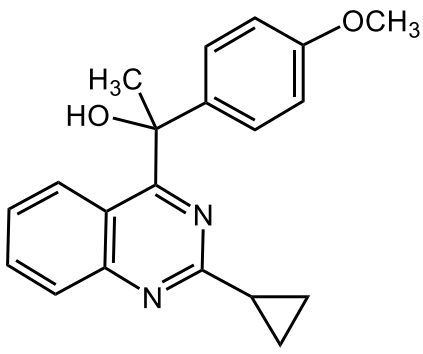

${ }^{1} \mathrm{H}-\mathrm{NMR}\left(300 \mathrm{MHz}, \mathrm{CDCl}_{3}\right) \delta: 1.18-1.26(2 \mathrm{H}, \mathrm{m}), 1.34-1.39(2 \mathrm{H}, \mathrm{m}), 2.06(3 \mathrm{H}, \mathrm{s}), 2.47(1 \mathrm{H}, \mathrm{tt}, J=8.1,4.7 \mathrm{~Hz})$, $3.78(3 \mathrm{H}, \mathrm{s}), 6.62(1 \mathrm{H}, \mathrm{s}), 6.84(2 \mathrm{H}, \mathrm{d}, J=8.8 \mathrm{~Hz}), 7.31-7.21(3 \mathrm{H}, \mathrm{m}), 7.61(1 \mathrm{H}, \mathrm{d}, J=8.5 \mathrm{~Hz}), 7.70(1 \mathrm{H}, \mathrm{ddd}, J=$ $8.3,6.9,1.4 \mathrm{~Hz}), 7.90(1 \mathrm{H}, \mathrm{d}, J=8.0 \mathrm{~Hz})$.

${ }^{13} \mathrm{C}-\mathrm{NMR}\left(126 \mathrm{MHz}, \mathrm{CDCl}_{3}\right) \delta: 10.77,10.84,18.4,28.4,55.3,74.5,113.9,119.3,125.8,126.4,127.7,128.4,133.3$, 137.5, 151.7, 158.97, 165.1, 172.3 .

HRMS (FAB) $m / z$ Calcd for $\mathrm{C}_{20} \mathrm{H}_{20} \mathrm{~N}_{2} \mathrm{O}_{2}\left(\mathrm{M}^{+}\right)$: 320.1525, Found: 320.1526 .

RT: 19.24 (EtOH: $\left.\mathrm{H}_{2} \mathrm{O}=1: 1,1 \mathrm{~mL} / \mathrm{min}\right)$.

\subsubsection{Synthesis of 1-(2-(furan-2-yl)quinazolin-4-yl)-1-(4-methoxyphenyl)ethan-1-ol (9d)}

According to the general procedure D, 9d $(22.5 \mathrm{mg}, 38 \%)$ was synthesized from $\mathbf{3 a}$ (53.8 $\mathrm{mg}, 0.171 \mathrm{mmol})$ and 2-furanboroic acid $(22.5 \mathrm{mg}, 0.201 \mathrm{mmol})$, using $\mathrm{PdCl}_{2}$ (dppf) dichloromethane adduct $(13.7 \mathrm{mg}, 0.0167 \mathrm{mmol}$ ) and aqueous potassium carbonate $(2.0 \mathrm{M}, 1.0 \mathrm{~mL})$ in 1,4-dioxane $(2.0 \mathrm{~mL})$. The reaction was conducted at reflux temperature for $14 \mathrm{~h}$. The titled compound was obtained as a brown oil.

${ }^{1} \mathrm{H}-\mathrm{NMR}\left(500 \mathrm{MHz}, \mathrm{CDCl}_{3}\right) \delta: 2.13(3 \mathrm{H}, \mathrm{s}), 3.78(3 \mathrm{H}, \mathrm{s}), 6.50(1 \mathrm{H}, \mathrm{s}), 6.65-6.67(1 \mathrm{H}$, m), $6.85(2 \mathrm{H}, \mathrm{t}, J=6.0 \mathrm{~Hz}), 7.29-7.35(3 \mathrm{H}, \mathrm{m}), 7.54(1 \mathrm{H}, \mathrm{d}, J=3.4 \mathrm{~Hz}), 7.68(1 \mathrm{H}, \mathrm{d}$,

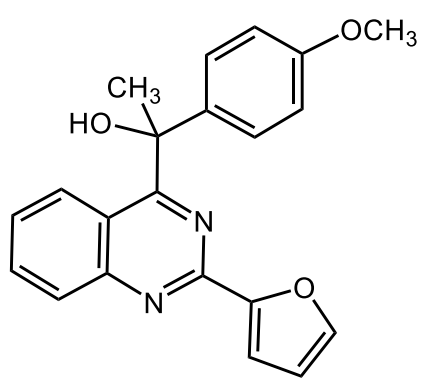
$J=8.5 \mathrm{~Hz}), 7.75(2 \mathrm{H}, \mathrm{dd}, J=13.9,4.3 \mathrm{~Hz}), 8.12(1 \mathrm{H}, \mathrm{d}, J=8.5 \mathrm{~Hz})$.

${ }^{13} \mathrm{C}-\mathrm{NMR}\left(126 \mathrm{MHz}, \mathrm{CDCl}_{3}\right) \delta: 28.6,55.4,75.0,112.5,114.1,114.8,119.7,126.8,126.9,127.9,129.5,133.9,137.3$, $145.8,151.1,151.8,152.1,159.2,173.1$.

HRMS (FAB) $m / z$ Calcd for $\mathrm{C}_{21} \mathrm{H}_{19} \mathrm{~N}_{2} \mathrm{O}_{3}(\mathrm{M}+\mathrm{H})^{+}: 347.1396$, Found: 347.1407 .

IR: $3360.00 \mathrm{~cm}^{-1}(\mathrm{OH})$.

RT: 16.38 (EtOH: $\left.\mathrm{H}_{2} \mathrm{O}=1: 1,1 \mathrm{~mL} / \mathrm{min}\right)$.

\subsubsection{Synthesis of 1-(2-(furan-3-yl)quinazolin-4-yl)-1-(4-methoxyphenyl)ethan-1-ol (PVHD303, 9e)}

According to the general procedure D, 9e (107 mg, 65\%) was synthesized from 3a (150 mg, $0.48 \mathrm{mmol}$ ) and 3-(4,4,5,5-tetramethyl-1,3,2-dioxaboran-2-yl)furan (93 $\mathrm{mg}, 0.48 \mathrm{mmol}$ ), using $\mathrm{PdCl}_{2}$ (dppf) dichloromethane adduct (29 $\left.\mathrm{mg}, 0.036 \mathrm{mmol}\right)$ and aqueous potassium carbonate $(2.0 \mathrm{M}, 1.0 \mathrm{~mL})$ in 1,4-dioxane $(4.0 \mathrm{~mL})$. The reaction was conducted at reflux temperature for $6 \mathrm{~h}$. The titled compound was obtained as a colorless solid.

Mp: $151-153{ }^{\circ} \mathrm{C}$.

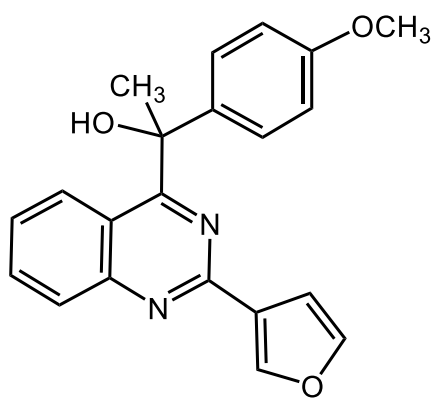

${ }^{1} \mathrm{H}-\mathrm{NMR}\left(500 \mathrm{MHz}, \mathrm{CDCl}_{3}\right) \delta: 2.15(3 \mathrm{H}, \mathrm{s}), 3.82(3 \mathrm{H}, \mathrm{s}), 6.65(1 \mathrm{H}, \mathrm{s}), 6.89(2 \mathrm{H}, \mathrm{d}, J=8.5 \mathrm{~Hz}), 7.29(1 \mathrm{H}, \mathrm{m}), 7.30-$ $7.34(1 \mathrm{H}, \mathrm{m}), 7.37(2 \mathrm{H}, \mathrm{d}, J=8.5 \mathrm{~Hz}), 7.62(1 \mathrm{H}, \mathrm{m}), 7.69(1 \mathrm{H}, \mathrm{d}, J=8.5 \mathrm{~Hz}), 8.04(1 \mathrm{H}, \mathrm{d}, J=8.5 \mathrm{~Hz}), 8.41(1 \mathrm{H}$, s), $8.04(1 \mathrm{H}, \mathrm{d}, J=8.5 \mathrm{~Hz})$.

${ }^{13} \mathrm{C}-\mathrm{NMR}\left(126 \mathrm{MHz}, \mathrm{CDCl}_{3}\right) \delta: 28.6,55.4,74.8,109.7,114.1,119.7,126.6,126.7,127.0,127.9,129.3,133.6,137.5$, 
$144.3,145.4,152.1,154.6,159.1,172.7$.

IR: $3336.55 \mathrm{~cm}^{-1}(\mathrm{OH})$.

HRMS (FAB) $m / z$ Calcd for $\mathrm{C}_{21} \mathrm{H}_{18} \mathrm{~N}_{2} \mathrm{O}_{3}(\mathrm{M})^{+}: 347.1317$, Found: 347.1315 .

RT: 26.85 (EtOH: $\mathrm{H}_{2} \mathrm{O}=1: 1,1 \mathrm{~mL} / \mathrm{min}$ ).

\subsubsection{Synthesis of 4-(4-(1-hydroxy-1-(4-methoxyphenyl)ethyl)quinazolin-2-yl)furan-2-carbaldehyde (9f)}

According to the general procedure D, 9 f $(90.6 \mathrm{mg}, 65 \%)$ was synthesized from 3a (117 mg, $0.372 \mathrm{mmol})$ and 5-formyl-2-furanboronic acid (70.7 $\mathrm{mg}, 0.505$ $\mathrm{mmol})$, using $\mathrm{PdCl}_{2}(\mathrm{dppf})$ dichloromethane adduct $(38.1 \mathrm{mg}, 0.052 \mathrm{mmol})$ and aqueous potassium carbonate $(2.5 \mathrm{M}, 2.0 \mathrm{~mL})$ in 1,4-dioxane $(4.0 \mathrm{~mL})$. The reaction was conducted at reflux temperature for $16 \mathrm{~h}$. The product was purified by silica gel column chromatography $(n$-hexane: ethyl acetate $=3: 1)$.

Mp: $195-196^{\circ} \mathrm{C}$.

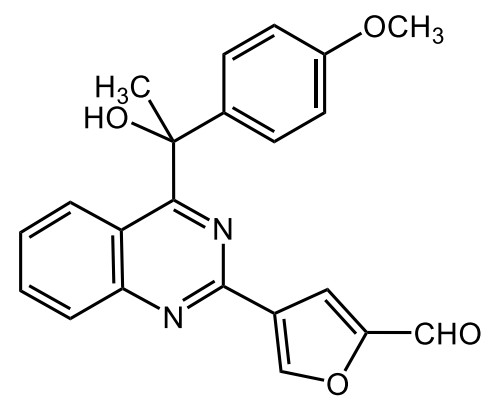

${ }^{1} \mathrm{H}-\mathrm{NMR}\left(300 \mathrm{MHz}, \mathrm{CDCl}_{3}\right) \delta: 9.95(1 \mathrm{H}, \mathrm{s}), 8.17(1 \mathrm{H}, \mathrm{d}, J=8.6 \mathrm{~Hz}), 7.83(1 \mathrm{H}, \mathrm{t}, J=7.7 \mathrm{~Hz}), 7.76(1 \mathrm{H}, \mathrm{d}, J=10.0$ $\mathrm{Hz}), 7.67(1 \mathrm{H}, \mathrm{d}, J=4.0 \mathrm{~Hz}), 7.47(1 \mathrm{H}, \mathrm{d}, J=4.0 \mathrm{~Hz}), 7.41(1 \mathrm{H}, \mathrm{t}, J=8.0 \mathrm{~Hz}), 7.35(2 \mathrm{H}, \mathrm{d}, J=8.6 \mathrm{~Hz}), 6.87(2 \mathrm{H}$, d, $J=4.3 \mathrm{~Hz}), 6.19(1 \mathrm{H}, \mathrm{s}), 3.80(3 \mathrm{H}, \mathrm{s}), 2.16(3 \mathrm{H}, \mathrm{s})$.

${ }^{13} \mathrm{C}-\mathrm{NMR}\left(75 \mathrm{MHz}, \mathrm{CDCl}_{3}\right) \delta: 28.9,55.3,75.4,114.1,115.7,120.3,126.9,127.7,127.8,129.8,134.1,137.1,150.2$, 151.6, 154.1, 156.0, 159.2, 173.6, 179.0, 207.0.

HRMS (ESI): $m / z$ Calcd for $\mathrm{C}_{22} \mathrm{H}_{19} \mathrm{~N}_{2} \mathrm{O}_{4}(\mathrm{M}+\mathrm{H})^{+}: 375.1345$, Found: 375.1337.

RT: 19.94 (EtOH: $\mathrm{H}_{2} \mathrm{O}=1: 1,1 \mathrm{~mL} / \mathrm{min}$ ).

\subsubsection{Synthesis of 1-(4-methoxyphenyl)-1-(2-(thiophen-2-yl)quinazolin-4-yl)ethan-1-ol (9g)}

According to the general procedure D, $9 \mathrm{~g}(33.6 \mathrm{mg}, 56 \%)$ was synthesized from $3 \mathbf{a}$ (49.4 $\mathrm{mg}, 0.165 \mathrm{mmol})$ and 2-thiopheneboronic acid (31.7 mg, $0.247 \mathrm{mmol})$, using $\mathrm{PdCl}_{2}(\mathrm{dppf})$ dichloromethane adduct $(13.1 \mathrm{mg}, 0.016 \mathrm{mmol})$ and aqueous potassium carbonate $(2.0 \mathrm{M}, 1.0 \mathrm{~mL})$ in 1,4-dioxane $(2.0 \mathrm{~mL})$. The reaction was conducted at reflux temperature for $4 \mathrm{~h}$. The titled compound was obtained as a brown solid.

${ }^{1} \mathrm{H}-\mathrm{NMR}\left(500 \mathrm{MHz}, \mathrm{CDCl}_{3}\right) \delta: 2.13(3 \mathrm{H}, \mathrm{s}), 3.78(3 \mathrm{H}, \mathrm{s}), 6.49(1 \mathrm{H}, \mathrm{s}), 6.65-6.66$ $(1 \mathrm{H}, \mathrm{m}), 6.86(2 \mathrm{H}, \mathrm{d}, J=6.8 \mathrm{~Hz}), 7.29-7.36(3 \mathrm{H}, \mathrm{m}), 7.54(1 \mathrm{H}, \mathrm{d}, J=3.4 \mathrm{~Hz}), 7.68$

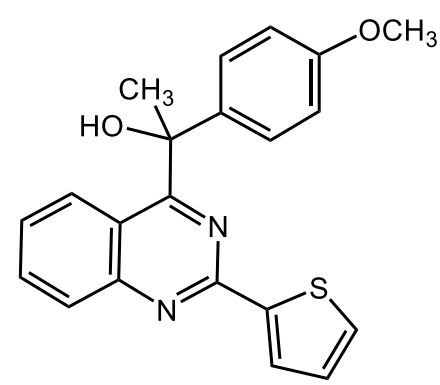
$(1 \mathrm{H}, \mathrm{d}, J=8.5 \mathrm{~Hz}), 7.75(2 \mathrm{H}, \mathrm{t}, J=8.5 \mathrm{~Hz}), 8.12(1 \mathrm{H}, \mathrm{d}, J=7.9 \mathrm{~Hz})$.

${ }^{13} \mathrm{C}-\mathrm{NMR}\left(126 \mathrm{MHz}, \mathrm{CDCl}_{3}\right) \delta: 28.6,55.4,74.9,112.5,114.1,114.8,119.7,126.8,126.9,127.9,129.5,133.9,137.4$, $145.8,151.1,151.8,152.1,159.2,173.1$.

IR: $3361.93 \mathrm{~cm}^{-1}(\mathrm{OH})$.

LRMS (ESI) m/z Calcd for $\mathrm{C}_{21} \mathrm{H}_{18} \mathrm{~N}_{2} \mathrm{NaOS}(\mathrm{M}-\mathrm{OH}+\mathrm{Na})^{+}$: 369, Found: 369.

RT: 16.64 (EtOH: $\left.\mathrm{H}_{2} \mathrm{O}=1: 1,1 \mathrm{~mL} / \mathrm{min}\right)$.

\subsubsection{Synthesis of 1-(2-(5-cyanothiophen-2-yl)quinazolin-4-yl)-1-(4-methoxyphenyl)ethan-1-ol (9h)}

According to the general procedure D, $9 \mathbf{h}(55.4 \mathrm{mg}, 49 \%)$ was synthesized from $\mathbf{3 a}(99.9 \mathrm{mg}, 0.317 \mathrm{mmol})$ and 5cyanothien-2-ylboroic acid $(57.9 \mathrm{mg}, 0.378 \mathrm{mmol})$, using $\mathrm{PdCl}_{2}(\mathrm{dppf})$ dichloromethane adduct $(28.3 \mathrm{mg}, 0.038$ $\mathrm{mmol}$ ) and aqueous potassium carbonate $(2.0 \mathrm{M}, 3.0 \mathrm{~mL})$ in 1,4-dioxane $(5.2 \mathrm{~mL})$. The reaction was conducted at 
reflux temperature for $14 \mathrm{~h}$.

Mp:207-209 ${ }^{\circ} \mathrm{C}$.

${ }^{1} \mathrm{H}-\mathrm{NMR}\left(300 \mathrm{MHz}, \mathrm{CDCl}_{3}\right) \delta: 2.14(3 \mathrm{H}, \mathrm{s}), 3.78(3 \mathrm{H}, \mathrm{s}), 5.85(1 \mathrm{H}, \mathrm{s}), 6.85(2 \mathrm{H}$, $\mathrm{d}, J=8.9 \mathrm{~Hz}), 7.71(1 \mathrm{H}, \mathrm{d}, J=3.8 \mathrm{~Hz}), 7.31-7.40(3 \mathrm{H}, \mathrm{m}), 7.78-7.82(2 \mathrm{H}, \mathrm{m}), 8.02-$ $8.05(1 \mathrm{H}, \mathrm{m}), 8.15(1 \mathrm{H}, \mathrm{d}, J=4.1 \mathrm{~Hz})$.

${ }^{13} \mathrm{C}-\mathrm{NMR}\left(126 \mathrm{MHz}, \mathrm{CDCl}_{3}\right) \delta: 29.1,55.3,75.6,112.7,114.0,114.2,120.4,127.1$,<smiles>COc1ccc(C(C)(O)c2nc(-c3ccc(C#N)s3)nc3ccccc23)cc1</smiles>
127.5, 127.6, 128.5, 129.4, 134.1, 137.1, 138.3, 150.1, 151.6, 153.1, 159.1, 173.4. HRMS (EI) $\mathrm{m} / \mathrm{z}$ Calcd for $\mathrm{C}_{22} \mathrm{H}_{17} \mathrm{~N}_{3} \mathrm{O}_{2} \mathrm{~S} \mathrm{M}^{+}: 387.1041$, Found: 387.1040 .

RT: 12.16 (EtOH: $\mathrm{H}_{2} \mathrm{O}=7: 3,1 \mathrm{~mL} / \mathrm{min}$ ).

\subsubsection{Synthesis of 1-(2-(5-chlorothiophen-2-yl)quinazolin-4-yl)-1-(4-methoxyphenyl)ethan-1-ol (9i)}

According to the general procedure D, $9 \mathbf{i}(31.6 \mathrm{mg}, 38 \%)$ was synthesized from $\mathbf{3 a}$ (65.3 mg, $0.207 \mathrm{mmol}$ ) and 5-chlorothien-2-ylboroic acid (35.0 mg, $0.216 \mathrm{mmol}$ ), using $\mathrm{PdCl}_{2}(\mathrm{dppf})$ dichloromethane adduct $(16.3 \mathrm{mg}, 0.023 \mathrm{mmol})$ and aqueous potassium carbonate $(2.0 \mathrm{M}, 1.0 \mathrm{~mL})$ in 1,4-dioxane $(2.5 \mathrm{~mL})$. The reaction was conducted at reflux temperature for $4.5 \mathrm{~h}$.

Mp: $128-129^{\circ} \mathrm{C}$.

${ }^{1} \mathrm{H}-\mathrm{NMR}\left(300 \mathrm{MHz}, \mathrm{CDCl}_{3}\right) \delta: 2.12(3 \mathrm{H}, \mathrm{s}), 3.78(3 \mathrm{H}, \mathrm{s}), 6.23(1 \mathrm{H}, \mathrm{s}), 6.85(2 \mathrm{H}, \mathrm{d}$,

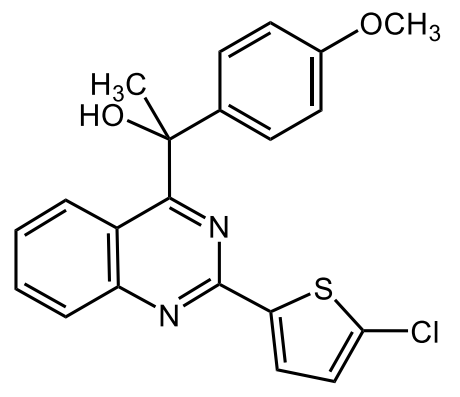
$J=9.0), 7.05(1 \mathrm{H}, \mathrm{d}, J=6.0), 7.33(2 \mathrm{H}, \mathrm{d}, J=9.0 \mathrm{~Hz}), 7.40(1 \mathrm{H}, \mathrm{d}, J=7.5 \mathrm{~Hz}), 7.68(1 \mathrm{H}, \mathrm{d}, J=6.0 \mathrm{~Hz}), 7.74(1 \mathrm{H}$, ddd, $J=8.4,6.9,1.5 \mathrm{~Hz}), 7.96-8.00(2 \mathrm{H}, \mathrm{m})$.

${ }^{13} \mathrm{C}-\mathrm{NMR}\left(126 \mathrm{MHz}, \mathrm{CDCl}_{3}\right) \delta: 28.8,55.2,75.2,114.0,119.8,126.6,126.8,127.7,127.7,128.6,129.0,133.8,134.8$, 137.3, 141.5, 151.8, 153.8, 159.0, 172.9.

HRMS (FAB) $m / z$ Calcd for $\mathrm{C}_{21} \mathrm{H}_{18} \mathrm{ClN}_{2} \mathrm{O}_{2} \mathrm{~S}(\mathrm{M}+\mathrm{H})^{+}: 397.0778$, Found: 397.0795 .

RT: 6.64 (EtOH: $\mathrm{H}_{2} \mathrm{O}=7: 3,1 \mathrm{~mL} / \mathrm{min}$ ).

\subsubsection{Synthesis of 1-(2-(2-acetylthiophen-3-yl)quinazolin-4-yl)-1-(4-methoxyphenyl)ethan-1-ol (9j)}

According to the general procedure D, $\mathbf{9 j}(82.1 \mathrm{mg}, 95 \%)$ was synthesized from $\mathbf{3 a}$ (67.0 mg, $0.212 \mathrm{mmol}$ ) and 2-acetylthien-3-ylboroic acid (54.5 mg, $0.320 \mathrm{mmol})$, using $\mathrm{PdCl}_{2}(\mathrm{dppf})$ dichloromethane adduct $(29.9 \mathrm{mg}, 0.040 \mathrm{mmol})$ and aqueous potassium carbonate $(1.0 \mathrm{M}, 3.0 \mathrm{~mL})$ in 1,4-dioxane $(4.0 \mathrm{~mL})$. The reaction was conducted at reflux temperature for $16 \mathrm{~h}$. The product was purified by silica gel column chromatography ( $n$-hexane: ethyl acetate $=3: 1)$.

$\mathrm{Mp}: 109-111^{\circ} \mathrm{C}$.

${ }^{1} \mathrm{H}-\mathrm{NMR}\left(300 \mathrm{MHz}, \mathrm{CDCl}_{3}\right) \delta: 2.13(3 \mathrm{H}, \mathrm{s}), 2.53(3 \mathrm{H}, \mathrm{s}), 3.79(3 \mathrm{H}, \mathrm{s}), 6.23(1 \mathrm{H}, \mathrm{s})$,

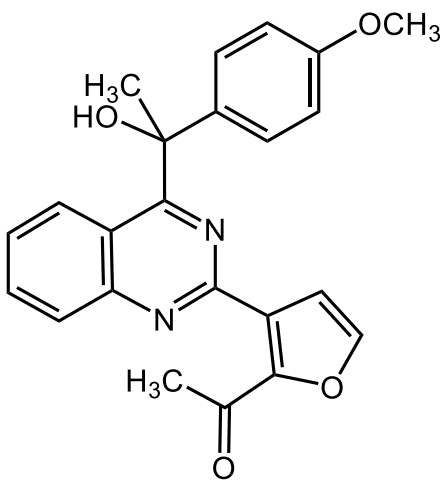
$6.87(2 \mathrm{H}, \mathrm{d}, J=8.9 \mathrm{~Hz}), 7.33-7.42(3 \mathrm{H}, \mathrm{m}), 7.60(1 \mathrm{H}, \mathrm{d}, J=5.0 \mathrm{~Hz}), 7.72(1 \mathrm{H}, \mathrm{d}, J=5.1 \mathrm{~Hz}), 7.76-7.83(2 \mathrm{H}, \mathrm{m})$, $8.06(1 \mathrm{H}, \mathrm{d}, J=8.5 \mathrm{~Hz})$.

${ }^{13} \mathrm{C}-\mathrm{NMR}\left(126 \mathrm{MHz}, \mathrm{CDCl}_{3}\right) \delta: 28.8,30.2,55.3,75.3,114.1,119.7,126.0,127.5,127.7,129.4,131.1,133.8,137.48$, 142.2, 143.2, 151.5, 155.8, 159.0, 172.9, 193.0 .

HRMS (FAB) $m / z$ Calcd for $\mathrm{C}_{23} \mathrm{H}_{21} \mathrm{~N}_{2} \mathrm{O}_{3} \mathrm{~S}(\mathrm{M}+\mathrm{H})^{+}: 405.1273$, Found: 405.1270 .

RT: 14.99 (EtOH: $\mathrm{H}_{2} \mathrm{O}=1: 1,1 \mathrm{~mL} / \mathrm{min}$ ). 


\subsubsection{Synthesis of 1-(2-(3,5-dimethylisoxazol-4-yl)quinazolin-4-yl)-1-(4-methoxyphenyl)ethan-1-ol (9k)}

According to the general procedure D, 9k $(67.9 \mathrm{mg}, 66 \%)$ was synthesized from 3a $(86.0 \mathrm{mg}, 0.273 \mathrm{mmol})$ and ,5-dimethylisozaxolylboroic acid $(45.6 \mathrm{mg}, 0.323$ $\mathrm{mmol})$, using $\mathrm{PdCl}_{2}(\mathrm{dppf})$ dichloromethane adduct $(24.9 \mathrm{mg}, 0.034 \mathrm{mmol})$ and aqueous potassium carbonate $(2.0 \mathrm{M}, 2.0 \mathrm{~mL})$ in 1,4-dioxane $(4.0 \mathrm{~mL})$. The reaction was conducted at reflux temperature for $15 \mathrm{~h}$.

Mp: $182-184{ }^{\circ} \mathrm{C}$.

${ }^{1} \mathrm{H}-\mathrm{NMR}\left(300 \mathrm{MHz}, \mathrm{CDCl}_{3}\right) \delta: 2.14(3 \mathrm{H}, \mathrm{s}), 2.77(3 \mathrm{H}, \mathrm{s}), 2.94(3 \mathrm{H}, \mathrm{s}), 3.79(3 \mathrm{H}, \mathrm{s})$,<smiles>COc1ccc(C(C)(O)c2nc(-c3c(C)noc3C)nc3ccccc23)cc1</smiles>
$5.98(1 \mathrm{H}, \mathrm{s}), 6.86(2 \mathrm{H}, \mathrm{d}, J=5.2 \mathrm{~Hz}), 7.32-7.35(3 \mathrm{H}, \mathrm{m}), 7.54-7.78(2 \mathrm{H}, \mathrm{m}), 8.00$ $(1 \mathrm{H}, \mathrm{dd}, J=5.4,0.9 \mathrm{~Hz})$.

${ }^{13} \mathrm{C}-\mathrm{NMR}\left(500 \mathrm{MHz}, \mathrm{CDCl}_{3}\right) \delta: 13.2,14.2,29.2,55.3,75.8,114.0,114.6,119.2,126.8,127.5,129.1,137.4,133.6$, $151.8,154.2,159.0,159.9,171.5,172.6$.

HRMS (EI) $m / z$ Calcd forC $\mathrm{C}_{22} \mathrm{H}_{21} \mathrm{~N}_{3} \mathrm{O}_{3}(\mathrm{M}+)$ : 375.1583 , Found: 375.1581 .

RT: 6.60 (EtOH: $\left.\mathrm{H}_{2} \mathrm{O}=7: 3,1 \mathrm{~mL} / \mathrm{min}\right)$.

\subsubsection{Synthesis of 1-[2-(1 H-pyrazole 3-yl)quinazoline-4-yl]-1-(4-methoxyphenyl)ethanol (9l)}

According to the general procedure D, 9l (134 mg, 99\%) was synthesized from 3a $(124 \mathrm{mg}, 0.394 \mathrm{mmol})$ and $1 H$-pyrazole-3-yl-boronic acid monohydrate $(58.3 \mathrm{mg}$, $0.495 \mathrm{mmol})$, using $\mathrm{Pd}\left(\mathrm{PPh}_{3}\right)_{4}(27.2 \mathrm{mg}, 0.0235 \mathrm{mmol})$ and potassium carbonate (201 $\mathrm{mg}, 1.46 \mathrm{mmol})$ in toluene $(4.0 \mathrm{~mL})$. The reaction was conducted at reflux temperature for $24 \mathrm{~h}$. The product was purified by silica gel column chromatography ( $n$-hexane: acetone $=72: 28)$.

Mp: $201-202^{\circ} \mathrm{C}$.<smiles>COc1ccc(C(C)(O)c2nc(-c3cn[nH]c3)nc3ccccc23)cc1</smiles>

${ }^{1} \mathrm{H}-\mathrm{NMR}\left(300 \mathrm{MHz}, \mathrm{CDCl}_{3}\right) \delta: 2.16(3 \mathrm{H}, \mathrm{s}), 3.78(3 \mathrm{H}, \mathrm{s}), 5.50(1 \mathrm{H}, \mathrm{s}), 6.59(1 \mathrm{H}, \mathrm{dd}, J=2.7,1.9 \mathrm{~Hz}), 6.86(2 \mathrm{H}, \mathrm{d}, J$ $=8.8 \mathrm{~Hz}), 7.29-7.37(3 \mathrm{H}, \mathrm{m}), 7.75-7.84(2 \mathrm{H}, \mathrm{m}), 7.93(1 \mathrm{H}, \mathrm{d}, J=1.4 \mathrm{~Hz}), 8.13(1 \mathrm{H}, \mathrm{d}, J=8.6 \mathrm{~Hz}), 8.80(1 \mathrm{H}, \mathrm{d}, J=$ $2.8 \mathrm{~Hz})$.

${ }^{13} \mathrm{C}-\mathrm{NMR}\left(126 \mathrm{MHz}, \mathrm{CDCl}_{3}\right) \delta: 29.5,55.3,76.2,108.7,114.0,120.0,126.4,127.2,127.4,129.1,129.5,134.4,137.1$, 144.0, 150.2, 152.7, 159.1, 175.8 .

HRMS (FAB) $m / z$ Calcd for $\mathrm{C}_{20} \mathrm{H}_{19} \mathrm{~N}_{4} \mathrm{O}_{2}(\mathrm{M}+\mathrm{H})^{+}: 347.1508$, Found: 347.1517 .

RT: 4.36 (EtOH: $\left.\mathrm{H}_{2} \mathrm{O}=7: 3,1 \mathrm{~mL} / \mathrm{min}\right)$. 


\subsubsection{Synthesis of 1-(2-(4-fluoropheny)quinazolin-4-yl) 1-(4-methoxyphenyl)ethan-1-ol (9m)}

According to the general procedure D, 9m $(57.7 \mathrm{mg}, 75 \%)$ was synthesized from $\mathbf{3 a}$ (64.9 mg, $0.206 \mathrm{mmol}$ ) and , 4-fluorophenylboroic acid (29.6 mg, $0.212 \mathrm{mmol}$ ), using $\mathrm{PdCl}_{2}$ (dppf) dichloromethane adduct $(18.2 \mathrm{mg}, 0.025 \mathrm{mmol})$ and aqueous potassium carbonate $(2.0 \mathrm{M}, 1.2 \mathrm{~mL})$ in 1,4-dioxane $(2.2 \mathrm{~mL})$. The reaction was conducted at reflux temperature for $2.5 \mathrm{~h}$.

Mp: $149-151^{\circ} \mathrm{C}$.

${ }^{1} \mathrm{H}-\mathrm{NMR}\left(300 \mathrm{MHz}, \mathrm{CDCl}_{3}\right) \delta: 2.09(3 \mathrm{H}, \mathrm{s}), 3.79(3 \mathrm{H}, \mathrm{s}), 5.76(1 \mathrm{H}, \mathrm{s}), 6.86(2 \mathrm{H}, \mathrm{d}, J$

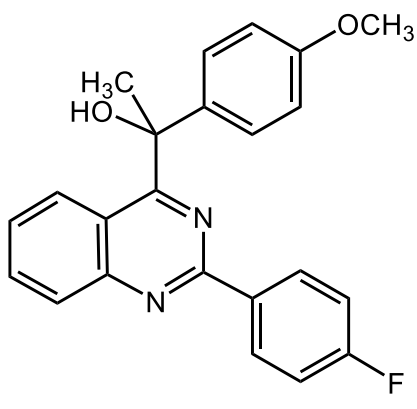
$=8.9 \mathrm{~Hz}), 7.21(1 \mathrm{H}, \mathrm{ddd}, J=8.1,6.9,1.2 \mathrm{~Hz}), 7.28-7.36(4 \mathrm{H}, \mathrm{m}), 7.44-7.50(2 \mathrm{H}, \mathrm{m}), 7.64-7.70(2 \mathrm{H}, \mathrm{m}), 7.77-7.80$ $(1 \mathrm{H}, \mathrm{m})$.

${ }^{13} \mathrm{C}-\mathrm{NMR}\left(126 \mathrm{MHz}, \mathrm{CDCl}_{3}\right) \delta: 28.7,55.3,75.2,114.0,115.7$ (d, $\left.J=21.2 \mathrm{~Hz}\right), 119.7,126.7$ (d, $\left.J=16.3 \mathrm{~Hz}\right), 127.7$, 129.5, 130.6, 133.5, 137.5, 152.1, 156.9, 159.0, $164.8(\mathrm{~d}, J=249.1 \mathrm{~Hz}), 172.7$.

HRMS (EI) $m / z$ Calcd for $\mathrm{C}_{23} \mathrm{H}_{19} \mathrm{FN}_{2} \mathrm{O}_{2}$ (M+): 374.1431, Found: 374.1426 .

RT: 9.84 (EtOH: $\left.\mathrm{H}_{2} \mathrm{O}=7: 3,1 \mathrm{~mL} / \mathrm{min}\right)$.

\subsubsection{1-(4-methoxyphenyl)-1-(2-(4-(trifluoromethyl)phenyl)quinazolin-4-yl)ethanol (9n)}

According to the general procedure D, $9 \mathbf{n}(52.5 \mathrm{mg}, 53 \%)$ was synthesized from $\mathbf{3 a}$ (73.9 mg, $0.235 \mathrm{mmol}$ ) and , 4-(trifluoromethyl)phenylboroic acid (49.8 mg, 0.262 mmol), using $\mathrm{PdCl}_{2}(\mathrm{dppf})$ dichloromethane adduct $(18.9 \mathrm{mg}, 0.026 \mathrm{mmol})$ and aqueous potassium carbonate $(2.5 \mathrm{M}, 1.0 \mathrm{~mL})$ in 1,4-dioxane $(4.0 \mathrm{~mL})$. The reaction was conducted at reflux temperature for $27 \mathrm{~h}$.

Mp: $224-225^{\circ} \mathrm{C}$.

${ }^{1} \mathrm{H}-\mathrm{NMR}\left(500 \mathrm{MHz}, \mathrm{CDCl}_{3}\right) \delta: 2.17(\mathrm{~s}, 3 \mathrm{H}), 3.79(\mathrm{~d}, J=1.1 \mathrm{~Hz}, 3 \mathrm{H}), 6.44(\mathrm{~s}, 1 \mathrm{H})$,<smiles>COc1ccc(C(C)(O)c2nc(-c3ccc(C(F)(F)F)cc3)nc3ccccc23)cc1</smiles>
$6.86(\mathrm{~d}, J=8.0 \mathrm{~Hz}, 2 \mathrm{H}), 7.37$ (q, $J=7.6 \mathrm{~Hz}, 3 \mathrm{H}), 7.80(\mathrm{td}, J=15.6,7.8 \mathrm{~Hz}, 4 \mathrm{H}), 8.13(\mathrm{~d}, J=8.6 \mathrm{~Hz}, 1 \mathrm{H}), 8.80(\mathrm{~d}$, $J=8.0 \mathrm{~Hz}, 2 \mathrm{H})$.

${ }^{13} \mathrm{C}-\mathrm{NMR}\left(125 \mathrm{MHz}, \mathrm{CDCl}_{3}\right) \delta: 28.8,55.2,75.3,114.0,120.1,124.1$ (q, $\left.J=272.3 \mathrm{~Hz}\right), 125.6,127.0(\mathrm{~d}, J=84.0$ Hz), 132.4 (d, $J=32.4 \mathrm{~Hz}), 127.7,128.8,129.7,133.8,137.3$, 140.6, 152.0,156.5, 159.1, 173.0, 207.0.

HRMS (ESI): $m / z[\mathrm{M}+\mathrm{H}]^{+}$Calcd for $\mathrm{C}_{24} \mathrm{H}_{20} \mathrm{~F}_{3} \mathrm{~N}_{2} \mathrm{O}_{2}: 425.1477$, Found: 425.1485 .

RT: 14.00 (EtOH: $\left.\mathrm{H}_{2} \mathrm{O}=7: 3,1 \mathrm{~mL} / \mathrm{min}\right)$.

\subsubsection{4-(4-(1-hydroxy-1-(4-methoxyphenyl)ethyl)quinazolin-2-yl)phenol (9o)}

According to the general procedure D, 90 (18.5 mg, 22\%) was synthesized from 3a (72.2 $\mathrm{mg}, 0.229 \mathrm{mmol})$ and 4-hydroxyphenylboronic acid (34.8 $\mathrm{mg}, 0.252 \mathrm{mmol})$, using $\mathrm{PdCl}_{2}$ (dppf) dichloromethane adduct $(17.9 \mathrm{mg}, 0.024 \mathrm{mmol})$ and potassium carbonate $(79.7 \mathrm{mg}, 0.577 \mathrm{mmol})$ in 1,4-dioxane $(4.0 \mathrm{~mL})$. The reaction was conducted at reflux temperature for 3 days.

Mp: $210-211^{\circ} \mathrm{C}$.

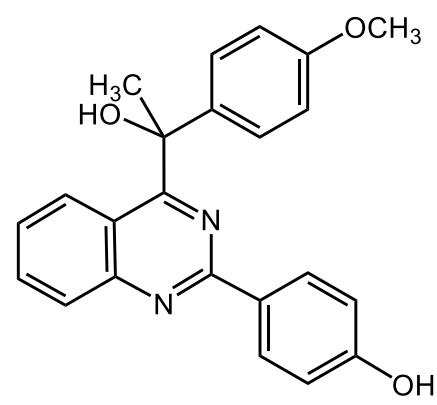

${ }^{1} \mathrm{H}-\mathrm{NMR}\left(500 \mathrm{MHz}, \mathrm{CDCl}_{3}\right) \delta$ : 2.15 (s, 3H), $3.78(\mathrm{~s}, 3 \mathrm{H}), 5.73(\mathrm{~s}, 1 \mathrm{H}), 6.85-6.87(\mathrm{~m}, 2 \mathrm{H}), 6.97(\mathrm{~s}, 1 \mathrm{H}), 7.02(\mathrm{~d}, J=$ $8.6 \mathrm{~Hz}, 2 \mathrm{H}), 7.29(\mathrm{td}, J=7.7,1.1 \mathrm{~Hz}, 1 \mathrm{H}), 7.35-7.37(\mathrm{~m}, 2 \mathrm{H}), 7.66(\mathrm{~d}, J=8.6 \mathrm{~Hz}, 1 \mathrm{H}), 7.73-7.76(\mathrm{~m}, 1 \mathrm{H}), 8.05(\mathrm{~d}$, $J=8.6 \mathrm{~Hz}, 1 \mathrm{H}), 8.59(\mathrm{~d}, J=8.0 \mathrm{~Hz}, 2 \mathrm{H})$. 
${ }^{13} \mathrm{C}-\mathrm{NMR}\left(100 \mathrm{MHz}, \mathrm{CDCl}_{3}\right) \delta: 28.4,55.2,76.8,114.0,115.7,119.4,126.4,126.5,127.9,129.3,129.8,130.5,133.5$, 137.2, 152.2, 157.6, 158.6, 159.1, 172.3 .

HRMS (ESI): $m / z[\mathrm{M}+\mathrm{H}]^{+}$Calcd for $\mathrm{C}_{23} \mathrm{H}_{21} \mathrm{~N}_{2} \mathrm{O}_{3}: 373.1552$, Found: 373.1537.

RT: 4.13 (EtOH: $\mathrm{H}_{2} \mathrm{O}=7: 3,1 \mathrm{~mL} / \mathrm{min}$ ).

\subsubsection{2-(4-(1-hydroxy-1-(4-methoxyphenyl)ethyl)quinazolin-2-yl)phenol (9p)}

According to the general procedure D, 9p $(21.4 \mathrm{mg}, 34 \%)$ was synthesized from 3a $(52.8 \mathrm{mg}, 0.168 \mathrm{mmol})$ and 2-hydroxyphenylboronic acid $(27.8 \mathrm{mg}, 0.202 \mathrm{mmol})$, using $\mathrm{PdCl}_{2}(\mathrm{dppf})$ dichloromethane adduct $(12.3 \mathrm{mg}, 0.017 \mathrm{mmol})$ and aqueous potassium carbonate $(2.5 \mathrm{M}, 1.0 \mathrm{~mL})$ in 1,4-dioxane $(4.0 \mathrm{~mL})$. The reaction was conducted at reflux temperature for $24 \mathrm{~h}$.

Mp: $145-146^{\circ} \mathrm{C}$.

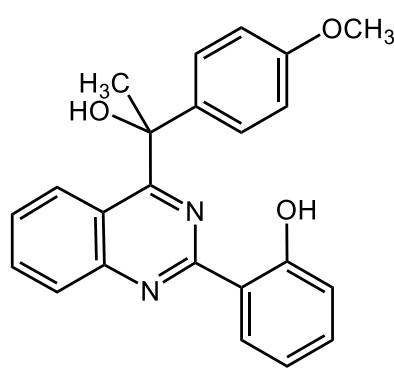

${ }^{1} \mathrm{H}-\mathrm{NMR}\left(500 \mathrm{MHz}, \mathrm{CDCl}_{3}\right) \delta: 2.17(\mathrm{~s}, 3 \mathrm{H}), 3.80(\mathrm{~s}, 3 \mathrm{H}), 6.11(\mathrm{~s}, 1 \mathrm{H}), 6.87(\mathrm{~d}, J=8.6 \mathrm{~Hz}, 2 \mathrm{H}), 7.06(\mathrm{t}, J=7.7 \mathrm{~Hz}$, 1H), 7.34-7.37 (m, 3H), $7.12(\mathrm{~d}, J=8.0 \mathrm{~Hz}, 1 \mathrm{H}), 7.47(\mathrm{t}, J=7.7 \mathrm{~Hz}, 1 \mathrm{H}), 7.78-7.81(\mathrm{~m}, 2 \mathrm{H}), 7.99(\mathrm{~d}, J=8.6 \mathrm{~Hz}$, $1 \mathrm{H}), 8.69(\mathrm{~d}, J=7.4 \mathrm{~Hz}, 1 \mathrm{H})$.

${ }^{13} \mathrm{C}-\mathrm{NMR}\left(100 \mathrm{MHz}, \mathrm{CDCl}_{3}\right) \delta: 29.1,55.3,114.1,118.0,118.6,119.1,127.0,127.1,127.6,127.8,129.4,133.6$, 134.2, 137.3, 149.0, 159.0, 159.1, 161.2, 173.5, 206.9.

HRMS (ESI): $m / z[\mathrm{M}+\mathrm{H}]^{+}$Calcd for $\mathrm{C}_{23} \mathrm{H}_{21} \mathrm{~N}_{2} \mathrm{O}_{3}: 373.1552$, Found: 373.1548 .

RT: 7.80 (EtOH: $\mathrm{H}_{2} \mathrm{O}=7: 3,1 \mathrm{~mL} / \mathrm{min}$ ).

\subsubsection{1-(2-(Benzo[d][1,3]dioxol-5-yl)quinazolin-4-yl)-1-(4-methoxyphenyl)ethanol (9q)}

According to the general procedure $\mathrm{D}, \mathbf{9 q}$ (111 $\mathrm{mg}$, quant.) was synthesized from $\mathbf{3 a}$ $(62.7 \mathrm{mg}, 0.199 \mathrm{mmol})$ and 3,4-(methylenedioxy)phenylboroic acid (43.8 mg, 0.264 mmol), using $\mathrm{PdCl}_{2}(\mathrm{dppf})$ dichloromethane adduct (29.5 mg, $\left.0.040 \mathrm{mmol}\right)$ and aqueous potassium carbonate $(2.5 \mathrm{M}, 4.0 \mathrm{~mL})$ in 1,4-dioxane $(4.0 \mathrm{~mL})$. The reaction was conducted at reflux temperature for $16 \mathrm{~h}$. The product was purified by silica gel column chromatography ( $n$-hexane: ethyl acetate $=3: 1)$.

Mp: $162-163^{\circ} \mathrm{C}$.

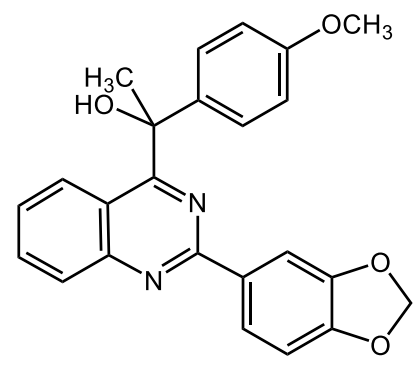

${ }^{1} \mathrm{H}-\mathrm{NMR}\left(500 \mathrm{MHz}, \mathrm{CDCl}_{3}\right) \delta: 2.14$ (s, 3H), $3.78(\mathrm{~s}, 3 \mathrm{H}), 6.09(\mathrm{~s}, 2 \mathrm{H}), 6.64(\mathrm{~s}, 1 \mathrm{H}), 6.85(\mathrm{~d}, J=9.2 \mathrm{~Hz}, 2 \mathrm{H}), 7.00$ $(\mathrm{d}, J=8.0 \mathrm{~Hz}, 1 \mathrm{H}), 7.29(\mathrm{t}, J=7.7 \mathrm{~Hz}, 1 \mathrm{H}), 7.34-7.36(\mathrm{~m}, 2 \mathrm{H}), 7.73-7.76(\mathrm{~m}, 1 \mathrm{H}), 7.68(\mathrm{~d}, J=8.6 \mathrm{~Hz}, 1 \mathrm{H}), 8.04(\mathrm{~d}$, $J=8.6 \mathrm{~Hz}, 1 \mathrm{H}), 8.16(\mathrm{~d}, J=1.1 \mathrm{~Hz}, 1 \mathrm{H}), 8.29(\mathrm{dd}, J=8.0,1.7 \mathrm{~Hz}, 1 \mathrm{H})$.

${ }^{13} \mathrm{C}-\mathrm{NMR}\left(125 \mathrm{MHz}, \mathrm{CDCl}_{3}\right) \delta: 172.4,159.0,157.3,152.1,150.1,148.3,137.5,133.4,131.7,129.4,127.8,126.6$, $126.4,123.5,119.6,114.0,108.6,108.4,101.6,75.0,55.2,28.6$.

HRMS (ESI): $m / z[\mathrm{M}+\mathrm{H}]^{+}$Calcd for $\mathrm{C}_{24} \mathrm{H}_{21} \mathrm{~N}_{2} \mathrm{O}_{4}: 401.1501$, Found: 401.1499 .

RT: 7.08 (EtOH: $\left.\mathrm{H}_{2} \mathrm{O}=7: 3,1 \mathrm{~mL} / \mathrm{min}\right)$. 


\subsubsection{Synthesis of 1-(4-methoxyphenyl)-1-(3-(pyridin-2-yl)quinazolin-4-yl)ethan-1-ol (9r)}

According to the general procedure D, 9r $(57.6 \mathrm{mg}, 85 \%)$ was synthesized from 3a (60 $\mathrm{mg}, 0.19 \mathrm{mmol})$ and 3-(4,4,5,5-tetramethyl-1,3,2-dioxaboran-2-yl)pyridine (43 mg, $0.21 \mathrm{mmol})$, using $\mathrm{PdCl}_{2}$ (dppf) dichloromethane adduct (13 $\left.\mathrm{mg}, 0.016 \mathrm{mmol}\right)$ and aqueous potassium carbonate $(2.0 \mathrm{M}, 1.0 \mathrm{~mL})$ in 1,4-dioxane $(4.0 \mathrm{~mL})$. The reaction was conducted at reflux temperature for $16 \mathrm{~h}$. The product was purified by silica gel column chromatography $(n$-hexane: ethyl acetate $=1: 1)$

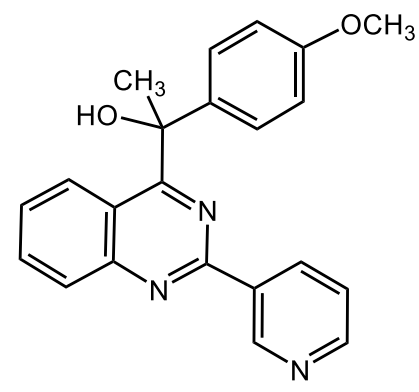
Mp: $211-213^{\circ} \mathrm{C}$.

${ }^{1} \mathrm{H}-\mathrm{NMR}\left(\mathrm{CDCl}_{3}\right) \delta: 2.17(3 \mathrm{H}, \mathrm{s}), 3.79(3 \mathrm{H}, \mathrm{s}), 6.36(1 \mathrm{H}, \mathrm{s}), 6.86(2 \mathrm{H}, \mathrm{d}, J=9.1 \mathrm{~Hz}), 7.34-7.39(3 \mathrm{H}, \mathrm{m}), 7.51(1 \mathrm{H}$, dd, $J=7.9,4.5 \mathrm{~Hz}), 7.78-7.83(2 \mathrm{H}, \mathrm{m}), 8.12(1 \mathrm{H}, \mathrm{d}, J=8.5 \mathrm{~Hz}), 8.78(1 \mathrm{H}, \mathrm{dd}, J=4.5,1.7 \mathrm{~Hz}), 8.92(1 \mathrm{H}, \mathrm{dt}, J=7.9$, $1.7 \mathrm{~Hz}), 9.88(1 \mathrm{H}, \mathrm{d}, J=1.7 \mathrm{~Hz})$.

${ }^{13} \mathrm{C}-\mathrm{NMR}\left(\mathrm{CDCl}_{3}\right) \delta: 29.0,55.4,75.5,114.1,120.3,123.6,126.9,127.4,127.8,129.7,133.0,133.9,135.8,137.5$, $150.3,151.6,152.1,156.2,159.2,173.2$.

IR: $3231 \mathrm{~cm}^{-1}(\mathrm{OH})$.

HRMS (EI) m/z Calcd for $\mathrm{C}_{22} \mathrm{H}_{19} \mathrm{~N}_{3} \mathrm{O}_{2}(\mathrm{M}+)^{+}: 357.1477$, Found: 357.1489 .

RT: 4.24 (EtOH: $\left.\mathrm{H}_{2} \mathrm{O}=7: 3,1 \mathrm{~mL} / \mathrm{min}\right)$. 


\section{Biology}

\subsection{Evaluation of growth inhibition by the quinazolines}

\subsubsection{Cell culture}

A549 cells (RIKEN BRC) were maintained in DMEM supplemented with 10\% (v/v) heat-inactivated fetal bovine serum, $1 \mathrm{mM}$ sodium pyruvate, $0.1 \mathrm{mM}$ non-essential amino acid and 20 units $/ \mathrm{mL}$ penicillin and $20 \mu \mathrm{g} / \mathrm{mL}$ streptomycin at $37^{\circ} \mathrm{C}$ in an atmosphere of $5 \% \mathrm{CO}_{2}$.

Hela cells and HCT116 cells (ATCC) were maintained in DMEM supplemented with 10\% (v/v) heat-inactivated fetal bovine serum and 20 units $/ \mathrm{mL}$ penicillin and $20 \mu \mathrm{g} / \mathrm{mL}$ streptomycin at $37^{\circ} \mathrm{C}$ in an atmosphere of $5 \% \mathrm{CO}_{2}$.

\subsubsection{Cell proliferation assay}

The cells (A549 $5 \times 10^{3}$ cells/well, HCT116 $2.5 \times 10^{3}$ cells/well) were seeded and treated with different concentrations of compounds for $72 \mathrm{hr}$. Cell proliferation was measured using a CellTiter 96 Aqueous One Solution Cell Proliferation Assay according to the manufacturer's protocol (Promega Corporation).

\subsubsection{Spindle and centrosome observation in 9e-arrested cells}

Hela cells were plated at $5 \times 104$ cells $/ \mathrm{ml}$ on cover glasses and cultured for $6 \mathrm{~h}$ before $9 \mathrm{e}$ treatment. To treat cells with $9 e$, the culture medium was replaced with pre-warmed $9 \mathrm{e}$-containing medium and incubated at $37^{\circ} \mathrm{C}$ in $5 \% \mathrm{CO} 2$ for 16-18 h. Cells were washed with phosphate-buffered saline (PBS), fixed with 4\% paraformaldehyde /PBS for 2 $\min$ and post-fixed with methanol at $-20^{\circ} \mathrm{C}$ for $8 \mathrm{~min}$.

Fixed cells were treated with $0.1 \%$ Triton X-100 in PBS for 30 min and subsequently with $10 \%$ fetal-bovine serum (FBS) and $0.1 \%$ Triton X-100 in PBS for $1 \mathrm{~h}$. They were then incubated with the primary antibody for $1 \mathrm{~h}$. Primary antibody used were rabbit polyclonal antibody against $\alpha$-tubulin (Thermo Fisher Scientific, Waltham, MA: RB-9281) [1:200] and goat polyclonal antibody against $\gamma$-tubulin (Santa Cruz, Santa Cruz, CA: sc-7396) [1:500]. Cells were then washed in $0.1 \%$ Triton X-100 in PBS three times and were incubated with Alexa Flour 488 or 568 donkey antirabbit or goat IgG (Thermo Fisher Scientific) [1:200] for $1 \mathrm{~h}$. All antibodies were diluted in 10\% FBS and 0.1\% Triton X-100 in PBS. For staining the chromosome, 4,6-diamidino-2-phenylindole (DAPI; Dojindo, Kumamoto, Japan) was supplemented in the secondary antibody solution at a concentration of $0.1 \mu \mathrm{g} / \mathrm{mL}$. After washing three times, cells were observed with a fluorescent microscope (AxioVert200M, Carl Zeiss).

\subsection{Evaluation of in vivo activity}

\subsubsection{Xenograft model}

Six-week-old male BALB/c nude mice were purchased from Japan SLC, Inc. Human colon cancer HCT116 cells (ATCC) were inoculated subcutaneously into the inguinal region of BALB/c nude mice $\left(2 \times 10^{6}\right.$ cells $/$ mouse). The long and short diameters of the tumor $(\mathrm{mm})$ were measured using calipers, and tumor volume was estimated at various times with the following equation: Estimated tumor volume $\left(\mathrm{mm}^{3}\right)=1 / 2 \times$ (long diameter) $\mathrm{x}$ (short diameter) ${ }^{2}$. When the tumor volume reached about $159 \mathrm{~mm}^{3}$ (Day 1), the inoculated mice were divided into test groups (5 mice/group). Compound 9 e [dissolved in 5\% glucose containing 10\% (w/v) Tween80 and 5\% (w/v) propylene glycol] was administered intravenously once a day on days $1,3,5,8,10,12,15,17$ and 19 . On day 22, a tumor was extirpated from each mouse and weighed, and the tumor growth inhibition rate, IR (\%), was derived from the following 
equation:

$\operatorname{IR}(\%)=[1-($ mean tumor weight of each treated group) / (mean tumor weight of control group) $] \mathrm{x} 100$.

Tumor volume was measured twice weekly during the experimental period.

All experiments with animals were conducted in accordance with the Guidelines of the Yakult Central Institute and protocols approved by the Animal Experimental Committee of the Yakult Central Institute.

\subsubsection{Statistical Analysis}

The statistical analysis was carried out using Dunnett's test. $P$ values less than 0.05 were considered significant. 


\section{References}

(1) Kuroiwa, K.; Ishii, H.; Matsuno, K.; Asai, A.; Suzuki, Y. Synthesis and structure-activity relationship study of 1phenyl-1-(quinazolin-4-yl)ethanols as anticancer agents. ACS Med. Chem. Lett. 2015, 6, 287-291.

(2) Arnott, E. A.; Chan, L. C.; Cox, B. G.; Meyrick, B.; Phillips, A. POCl 3 chlorination of 4-quinazonones. J. Org. Chem. 2011, 76, 1653-1661.

(3) Rinderapacher, K. A.; Yu, W.; Duff, K.; Landry, D.; Deng, S.-X. Activators of autophagic flux and phospholipase $\mathrm{D}$ and clearance of protein aggregates including tau and treatment of proteinopathies. U.S. Pat. Appl. Publ., 27 Jul 2017, 20170210759.

(4) Zhang, Q.; Li, Y.; Zhang, B.; Lu, B.; Li, J. Design, synthesis and biological evaluation of novel histone deacetylase inhibitors incorporating 4-aminoquinazolinyl systems as capping groups. Bioorg. Med. Chem. Lett. 2017, 27, 4885-4888.

(5) Takase, Y.; Saeki, T.; Watanabe, N.; Adachi, H.; Souda, S.; Saito, I. Cyclic GMP phosphodiesterase inhibitors. 2. Requirement of 6-substitution of quinazoline derivatives for potent and selective inhibitory activity. J. Med. Chem. 1994, 37, 2106-2111.

(6) Lippa, B.; Kauffman, G. S.; Arcari, J.; Kwan, T.; Chen, J.; Hungerford, W.; Bhattacharya, S.; Zhao, X.; Williams, C.; Xiao, J.; Pustilnik, L.; Su, C.; Moyer, J. D.; Ma, L.; Campbell, M.; Steyn, S. The discovery of highly selective erbB2 (Her2) inhibitors for the treatment of cancer. Bioorg. Med. Chem. Lett. 2007, 17, 3081-3086.

(7) Humphrey, J. M.; Yang, E.; am Ende, C. W.; Arnold, E. P.; Head, J. L.; Jenkinson, S.; Lebel, L. A.; Liras, S.; Pandit, J.; Samas, B.; Vajdos, F.; Simons, S. P.; Evdokimov, A.; Mansour, M.; Menniti, F. S. Small-molecule phosphodiesterase probes: discovery of potent and selective CNS-penetrable quinazoline inhibitors of PDE1. MedChemComm 2014, 5, 1290-1296.

(8) Ewing, W. R.; Becker, M. R.; Choi-Sledeski, Y. M.; Pauls, H. W.; He, W.; Condon, S. M.; Davis, R. S.; Hanney, B. A.; Spada, A. P.; Burns, C. J.; Jiang, J. Z.; Li, A.; Myers, M. R.; Lau, W. F.; Poli, G. B. Substituted piperazinone derivatives and other oxoazaheterocyclyl compounds useful as factor Xa inhibitors. PCT Int. Appl. 29 Jul 1999, 9937304.

(9) Kuemmerle, A. E.; Vieira, M. M.; Schmitt, M.; Miranda, A. L. P.; Fraga, C. A. M.; Bourguignon, J.-J.; Barreiro, E. J. Design, synthesis and analgesic properties of novel conformationally-restricted N-acylhydrazones (NAH). Bioorg. Med. Chem. Lett. 2009, 19, 4963-4966.

(10) Berg, M.; Bal, G.; Goeminne, A.; Van der Veken, Pi.; Versees, W.; Steyaert, J.; Haemers, A.; Augustyns, K. Synthesis of bicyclic N-arylmethyl-substituted iminoribitol derivatives as selective nucleoside hydrolase inhibitors. MedChemComm 2009, 4, 249-260.

(11) Tangirala, R.; Antony, S.; Agama, K.; Pommier, Y.; Curran, D. P. Total synthesis of luotonin and a small library of AB-ring substituted analogs by cascade radical annulation of isonitriles. Synlett 2005, 2843-2846. 